\title{
Crack Growth Rate and Crack Path in Adhesively Bonded Joints: Comparison of Creep, Fatigue and Fracture
}

Minseok "Greg” Jhin

A thesis submitted in conformity with the requirements

for the degree of Master of Applied Science

Mechanical and Industrial Engineering

University of Toronto

(C) Copyright by Minseok Jhin 2012 


\title{
Crack Growth Rate and Crack Path in Adhesively Bonded Joints: Comparison of Creep, Fatigue and Fracture
}

\author{
Minseok "Greg” Jhin \\ Master of Applied Science \\ Mechanical and Industrial Engineering \\ University of Toronto \\ 2012
}

\begin{abstract}
The relationship between crack path and test method was examined by comparing the performance of adhesive-adherend combinations (six) in quasi-static fracture, mixed-mode fatigue, and creep crack growth. Crack paths in creep and quasi-static fracture were similar due to similar crack-tip plastic zone sizes in the epoxy adhesive even though the crack growth rates in creep were much smaller. Under condensed moisture and mixed-mode, creep and threshold fatigue tests produced interfacial failure. Under room-temperature dry environment, near threshold mixed-mode fatigue was interfacial, but was not in creep or quasi-static fracture. Smaller plastic zone size and crack path proximity to the interface that followed increased the sensitivity of near threshold, mixed-mode fatigue to surface properties. Therefore, the interfacial or cohesive failure of an adhesive system, which may judge the quality of the bond, can be a function of the test being conducted and may not be an absolute indicator of joint quality.
\end{abstract}




\section{Acknowledgements}

I would like to thank Professor Spelt and Professor Papini for their undivided attention to the progress of my research from my just starting learning about the theoretical and practical aspects of adhesive joints until the submission of my first journal paper. Without their direction and contribution, this thesis and its paper counter-part could not have reached the level of caliber and attention to detail that it has reached now. Although they probably deserve more than a brief mention, I would also like to thank all my previous and current lab mates who have been such a great help explaining to me all the theoretical and practical aspects of fracture mechanics, and how can I forget the innumerable hours spent on discussing research, science, politics and life in general. They are, without the order of importance: Siva Prasad Varma Nadimpalli, Naresh Varma Datla, Amirhossein Mohajerani, Amir Ameli, Shahrokh Azari, Hooman Nouraei, Amir Nourani, Reza H.M. Jafar, Kamyar Hashemnia, Kavin Kowsari, and Shiksha Rai. Last but not least, I thank Dr. A. Hull at Engineering Material Research who provided very helpful support during the fatigue and creep experiments. Acknowledgements are also due to the Natural Sciences and Engineering Research Council of Canada and General Motors of Canada for their financial support. 


\section{Table of Contents}

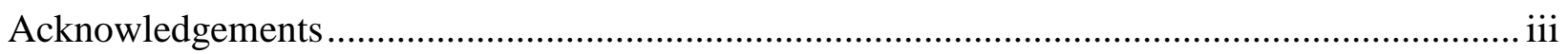

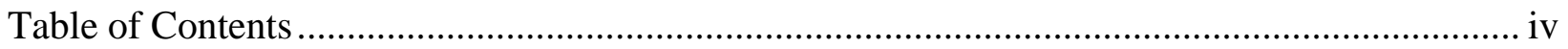

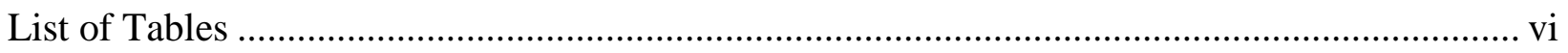

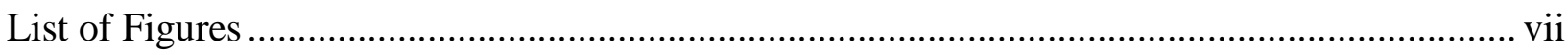

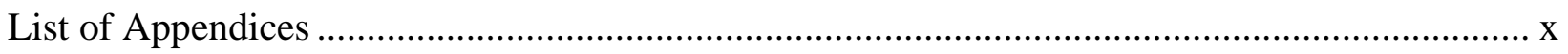

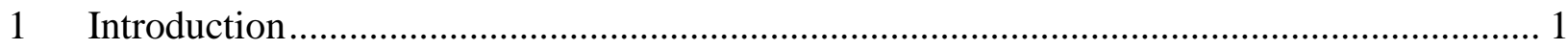

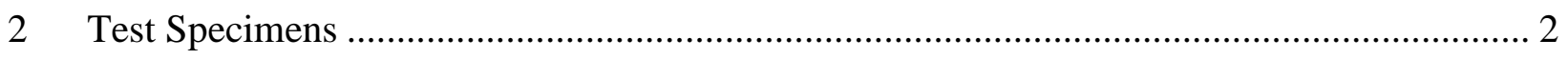

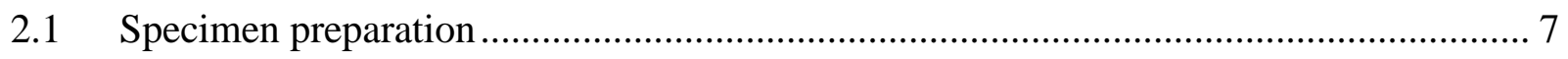

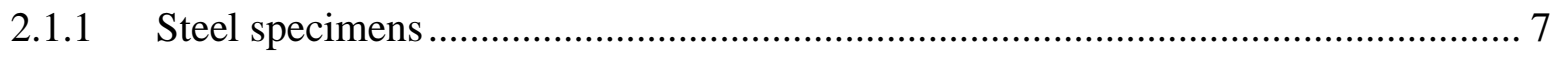

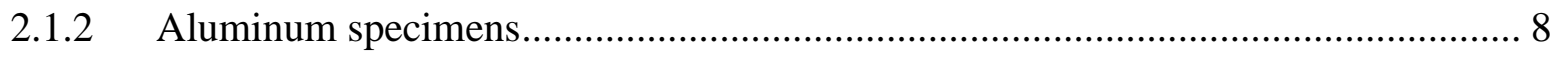

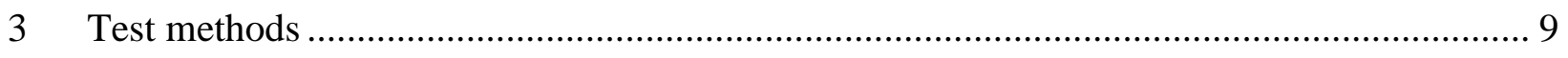

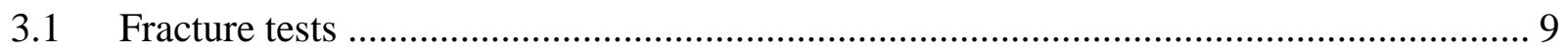

Fixed-displacement creep crack growth tests.................................................... 10

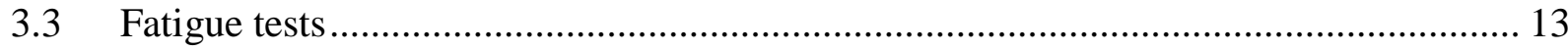

3.4 Residual adhesive thickness measurement..................................................... 14

3.5 Strain energy release rate and mode ratio calculations ........................................ 15

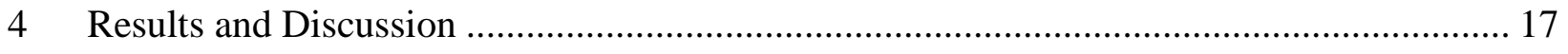

4.1 Comparison of Crack Paths in Fracture, Creep and Fatigue - Effect of crack-tip plastic

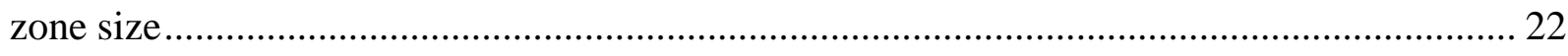




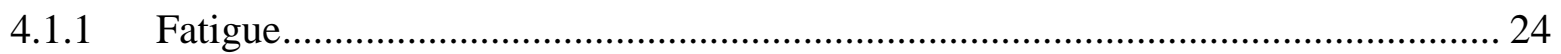

4.1.2 Creep crack growth ............................................................................. 24

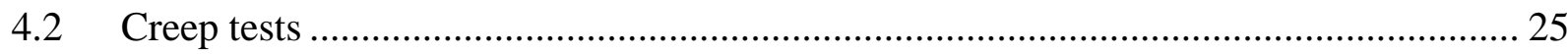

4.2.1 Effect of environment on the P2-etched AA6061-T6 system............................. 27

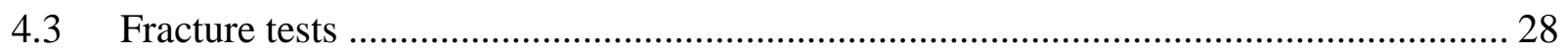

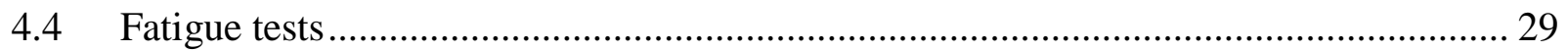

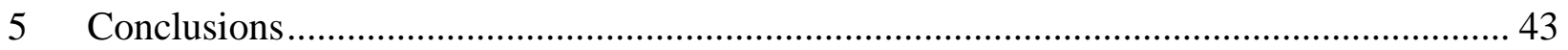

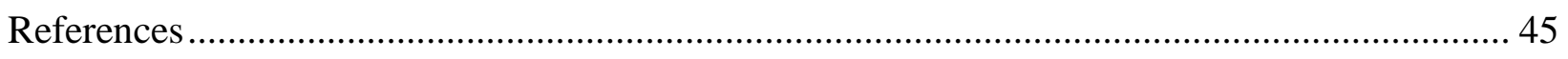

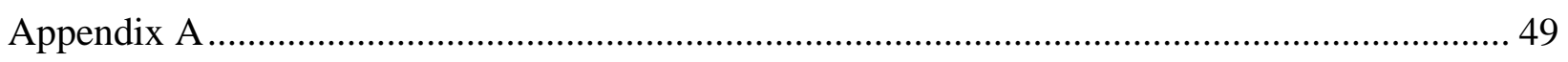

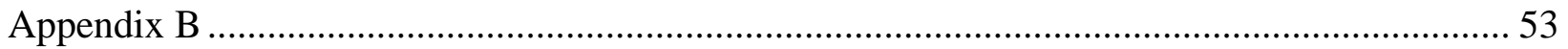




\section{List of Tables}

Table 1 Tests performed on each type of adhesive joint. Most results for degreased 1018 steel bars came from observations of the opposing adherend surface in reinforced steel sheet specimens. Only some DCBs in fatigue were made entirely of degreased 1018 steel bars. 14

Table 2 Material properties used in calculating the strain energy release rate. The adhesive properties were obtained from the manufacturer. 15

Table 3 Quasi-static fracture tests under mode I or very small mode ratios. DP600 and AA5754O were sheet adherends. $G_{c s}$ is the mean value among the samples and SD is one standard deviation. $N$ is the total number of experiments performed with all specimens. Tests 6,7 and 8 are results taken from ref. [6].

Table 4 Creep crack growth results. Average $G_{a}$ and $G_{c s}$ grouped in categories defined by the loading, phase angle, environment and adherend material. All specimens were either DCB for aluminum bars, or rDCB for sheet adherends, and all tests started at $100 \% G_{c s} . \mathrm{Al}-\mathrm{P} 2$ etch AA6061-T6 bars, DP - Degreased DP600 sheet reinforced with degreased AISI 1018 steel. RD room-dry $\left(25^{\circ} \mathrm{C} 10 \%-\mathrm{RH}\right), \mathrm{HD}$ - hot-dry $\left(40^{\circ} \mathrm{C} 10 \%-\mathrm{RH}\right), \mathrm{HH}$ - hot-humid $\left(40^{\circ} \mathrm{C} 95 \%-\mathrm{RH}\right)$, and HW - hot-wet $\left(40^{\circ} \mathrm{C} 100 \%-\mathrm{RH}\right) . \mathrm{LJ}$ - load jig; W - wedge loading; LF - servo-hydraulic load frame. The variables $m$ and $b$ are for the curve fits of Figure 8. $N$ is the number of experiments, $(S)$ is the number of specimens. $G_{a} / G_{c s}$ represents the ratio of average $G_{a}$ to average $G_{c s}$

Table 5 Fatigue test results for steel and aluminum adherends. $\psi=13^{\circ}$ for all aluminum specimens and $\psi=11^{\circ}$ for all steel specimens. Results for AISI steel from [9] and [7] as indicated. The effect of mode ratio on $G_{t h}$ was negligible below $27^{\circ}$ [7]. $S$ indicates number of specimens. Each specimen was used to perform one experiment.

Table 6 Tests performed on each type of adhesive joint. Fatigue and creep tests done with continuously decreasing applied $G$ to approach fatigue threshold $\left(G_{t h}\right)$ or crack arrest $\left(G_{a}\right)$, respectively. RD - room temperature dry; $\mathrm{HD}$ - hot, dry; $\mathrm{HH}$ - hot, humid; HW - hot, wet..... 23 


\section{List of Figures}

Figure 1 DCB configuration used for AA6061-T6 specimens in fracture and creep. All dimensions in mm, unless stated.

Figure 2 Mixed-mode load jig used with the screw-driven servo-electric load frame in fracture and creep experiments [16].

Figure 3 rDCB configuration used for $2 \mathrm{~mm}$ thick hot-dipped galvanized DP600 and coil-coated AA5754 sheet adherends in fracture, fatigue and creep tests. All dimensions in mm, unless stated.

Figure 4 ADCB configuration used for fatigue testing aluminum AA6061-T6 adherends. All dimensions in mm, unless stated

Figure 5 rADCB configuration used for fatigue testing of $2 \mathrm{~mm}$ thick sheets of bare AA5754, coil coated AA5754, etched galvanized DP600, and Bonderite ${ }^{\mathrm{TM}}$ coated galvanized DP600. All dimensions in mm, unless stated.

Figure 6 Wedge test on DCB specimen. The displacement induced by the wedge on each arm was $\left(\delta-h_{a}\right) / 2$. $\delta$ was either $3.1 \mathrm{~mm}$ or $6.1 \mathrm{~mm}$. $\theta$ was $28^{\circ}$ for $\delta=3.1 \mathrm{~mm}$ and $50^{\circ}$ for $\delta=6.1 \mathrm{~mm}$. Line contact with DCB arms was made at A and B. The wedge width was the same as the specimen width. All dimensions in mm.

Figure 7 Mode I quasi-static fracture surfaces of: (a) P2 etched AA6061-T6, (b) sulphuric acid etched DP600 $\left(\psi=3^{\circ}\right)$ bonded to AISI steel bar and (c) coil coated AA5754-O $\left(\psi=4^{\circ}\right)$. Steadystate $G_{c s}$ data were collected between the white and black triangles.

Figure 8 Crack speed vs. $G$ for creep tests. RD indicates room-dry $\left(25^{\circ} \mathrm{C} 10 \% \mathrm{RH}\right)$. Test progresses from right to left. RD mode I (load jig) is category 1 of Table 4, RD mixed (load jig, $27^{\circ}$ ) is category 2 , RD mode I (wedge) is category 3, and RD DP600 is category 4 . All mode I 
and all mixed-mode Data were fitted to the equation $\log (\mathrm{d} a / \mathrm{d} t)=m G+b$ where $m$ and $b$ are given in categories 1 and 2 in Table 4. Creep arrest was defined to be at $\log (\mathrm{d} a / \mathrm{d} t)=-5.4$.

Figure 9 Environmental mode I creep test data from test in servo-hydraulic load frame. RD indicates room-dry $\left(25^{\circ} \mathrm{C} 10 \% \mathrm{RH}\right)$, HD indicates hot dry $\left(40^{\circ} \mathrm{C} 10 \% \mathrm{RH}\right), \mathrm{HH}$ indicates hot humid $\left(40^{\circ} \mathrm{C} 95 \% \mathrm{RH}\right)$, and $\mathrm{HW}$ indicates hot wet $\left(40^{\circ} \mathrm{C} 100 \% \mathrm{RH}\right)$. Data were fitted to the equation $\log (\mathrm{d} a / \mathrm{d} t)=m G+b$ where $m$ and $b$ are given in categories 7, 8, 9 and 10 in Table 4 . Creep arrest was defined to be at $\log (\mathrm{d} a / \mathrm{d} t)=-5.4$.

Figure 10 Creep crack growth failure surfaces. Each white and black triangle pair represent points at which $G_{c s}$ and $G_{a}$ were measured, respectively. (a) specimen 1: two mode-I load jig tests in RD (Table 4 category 1); two mixed-mode load jig tests in RD (Table 4 category 2); one wedge test in RD (Table 4 category 3); and one wedge test in HD environment (Table 4 category 5) (b) specimen 3: wedge test in RD (Table 4 category 3); wedge test in HD (Table 4 category 5); and wedge test in HW (Table 4 category 6) (c) specimen 5: DP600 and AISI1018 mode-I load jig tests in RD (Table 4 category 4$)$.

Figure 11 Creep failure surfaces of AA6061-T6 bars in: (a) RD (25 $\left.{ }^{\circ} \mathrm{C} 10 \%-\mathrm{RH}\right)$ (Table 4 category 8), (b) $\mathrm{HD}\left(40^{\circ} \mathrm{C} 10 \%-\mathrm{RH}\right)$ (Table 4 category 9), (c) $\mathrm{HH}\left(40^{\circ} \mathrm{C} 95 \%-\mathrm{RH}\right)$ (Table 4 category 10$)$, and (d) $\mathrm{HW}\left(40^{\circ} \mathrm{C} 100 \%-\mathrm{RH}\right)$ (Table 4 category 11$)$. All tests were mode I and were done on the hydraulic load frame. White and black triangles indicate start and end of a $24 \mathrm{~h}$ creep test respectively. 36

Figure 12 Fatigue crack growth for aluminum ADCB joints. Al indicates P2-etched AA6061-T6, CC 5754 indicates coil-coated AA5754-O, and AA5754 indicates degreased AA5754-O.

Figure 13 Mixed-mode fatigue failure surfaces of: (a) P2-etched AA6061-T6, (b), (c) bare degreased AA5057-O, (d) Coil-coated AA5754-O (Table 5). Test starts at the white triangle. White chevron indicates first instant crack front reaches the interface, and black chevron indicates first instant that $100 \%$ of crack front lands on the interface. Final threshold is indicated by black triangle. All tests at a phase angle of approximately $12^{\circ}$. Specimen was quasi-statically fractured after threshold (right of black triangle) at this phase angle. 38

Figure 14 Fatigue crack growth for sulfuric acid etched DP600 specimens 39 
Figure 15 Fatigue crack growth for Bonderite coated DP600 specimens

Figure 16 Fatigue failure surfaces of: (a) acid-etched DP600-2, (b) acid-etched DP600-3, (c) Bonderite $^{\mathrm{TM}}$ specimen 1, (d) Bonderite ${ }^{\mathrm{TM}}$ specimen 2 (Table 5). White chevron indicates first instant that part of crack front reached the interface, and black chevron indicates first instant that $100 \%$ of crack front reached the interface. Black triangle indicates threshold. All tests at a phase angle of approximately $12^{\circ}$. Specimen was quasi-statically fractured after threshold (right of black triangle) at this phase angle.

Figure 17 Residual adhesive thickness measurements along the centerline as a function of distance from the loading pins. Mode I, room temperature dry creep test of P2 etched AA6061 specimen tested on the load jig (Table 4 category 1). Equation of line of best fit shown on graph.

Figure 18 Residual adhesive thickness measured along the centerline as a function of distance from the loading pins. Surface was on the more highly-strained adherend for a mixed-mode ( $\Psi=$ $27^{\circ}$ ) creep specimen (room temperature dry test, P2-etched AA6061) specimen tested on the load jig (Table 4 category 2). Equation of line of best fit shown on graph. 


\section{List of Appendices}

Appendix A Calculations of Specimen Loads, Strain Energy Release rates and Mode Ratios... 49

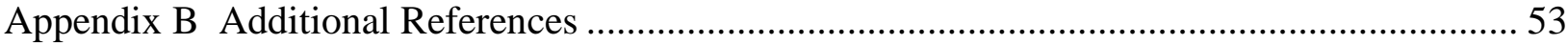




\section{Introduction}

The strength and quality of adhesive joints is frequently measured in terms of the loads corresponding to quasi-static fracture, or to a given rate of crack growth, either in fatigue or while subject to creep conditions under a constant load. Adhesive joint quality is usually associated with the observed crack path, with cohesive cracks within the adhesive layer being desirable and interfacial cracks being considered unacceptable since they indicate that the cohesive strength of the adhesive is not being fully exploited.

Fracture in adhesive joints is often characterized by the critical strain energy release rate for crack extension, $G_{c}$ [1], which is a function of the mode ratio of loading [2][3][4][5]. Such crack growth in toughened epoxy adhesive joints can display a bi-linear R-curve where crack growth initiates at $G_{c i}$, and increases linearly to a steady-state value $G_{c s}$ [2]. This toughening of the joint is explained by an increase in the damage zone that extends from the crack tip as the crack grows. An increase in the mode ratio (relative amounts of shear to opening crack tip stress), causes $G_{c s}$ and $G_{c i}$ to grow [3][4][5], and lengthens the rising part of the R-curve [2]. Of particular note is the shift in the average crack path toward the more highly-strained adherend as the mode ratio increases [1][3]. This is caused by the asymmetry of the adherend bending loads under mixed-mode conditions, which in turn causes the crack tip to follow an inclined path that is normal to the principal stress until it becomes deflected by the adherend. Crack paths have been found to be flatter for more brittle adhesive behavior where the plastic zone is smaller (i.e. smoother failure surfaces) and more three-dimensional for tougher adhesives having a larger plastic zone [6].

Crack path selection in fatigue displays many of the same characteristics as in quasi-static fracture with the notable exception that the damage zone tends to be smaller; particularly as the crack speed approaches the fatigue threshold. It has been hypothesized that this smaller plastic zone permits the crack path to move closer to the more highly-strained adherend than in fracture, thus explaining the observation that mixed-mode fatigue is extremely sensitive to the condition of the bond interface [7][8][9][10][11][12]. For example, DCB joints made with degreased AISI 
1018 steel failed cohesively in quasi-static fracture, but interfacially in fatigue testing near the threshold under the same mode ratio [8]. Similar observations were made in a comparison of quasi-static fracture with cyclic fatigue using 2024-T351 aluminum adherends that were anodized with phosphoric acid before bonding with one of three epoxy adhesives. Alternating the two loading conditions caused an alternating locus of failure: quasi-static fracture was accompanied by cohesive failure, and cyclic loading generated interfacial failure [13].

Under constant load or a fixed displacement, slow, time-dependent growth of cracks can occur in adhesive joints by creep mechanisms. Under fixed displacement, crack growth has been observed in toughened epoxies at values of the applied strain energy release rate, $G$, well below the steady-state critical value in fracture, $G_{c s}[14]$. In earlier work with two epoxy adhesives, the threshold value of $G$ (i.e. $G$ at crack arrest under creep loading, $G_{a}$ ) was found to be a constant fraction of the quasi-static critical fracture energy $G_{c s}$, independent of the mode ratio [9]. Therefore, testing at one mode ratio to measure the fraction of $G_{c s}$ for zero (or an acceptably small) creep crack growth could be used to estimate the threshold value of $G$ at other mode ratios.

The present work compared the effect of mode ratio, adherend material, pretreatment, and test environment on crack growth in adhesive joints subject to three types of tests: quasi-static fracture, fatigue, and creep. The main objective was to understand how the crack path and failure mode for a given adhesive joint system can depend on the type of loading.

\section{Test Specimens}

The adhesive and adherends used in the experiments were typical of those in automotive manufacturing. The adhesive layer thickness was typical of that found in adhesive joints in automotive assembly.

A variety of specimen configurations were tested, using adherends made from both an aluminum alloy and a steel alloy. The double cantilever beam (DCB) configuration shown in Figure 1 
generated mode I crack growth in the adhesive layer when equal loads were applied to the adherends. This same DCB specimen was also used in the investigation of mixed-mode quasistatic fracture and creep crack growth by applying unequal loads to the adherends using the load jig of Figure 2. In this case, various loading mode ratios could be established with a single DCB by suitably altering the pin locations as described in ref. [15].

The reinforced DCB (rDCB) configuration shown in Figure 3 allowed the investigation of adhesive joints with hot-dipped galvanized DP600 and coil-coated AA5754 sheet adherends that would have otherwise yielded at some of the loads used in the fracture, fatigue and creep tests. In ref. [9] it was established that the rDCB specimen produced the same fracture and fatigue results as a conventional DCB made from monolithic adherends. The slight asymmetry of the upper and lower adherends introduced a negligibly small mode II component to the loading when equal loads were applied to the adherends; i.e. the phase angle, $\Psi$, in this case was approximately $4^{\circ}$, where the phase angle is a commonly used measure of the mode ratio of the loading defined as

$\psi=\arctan \left(\sqrt{G_{I I} / G_{I}}\right)=\arctan \left(K_{I I} / K_{I}\right)$

Here, $G_{I}, K_{I}, G_{I I}$ and $K_{I I}$ are, respectively, the mode I and mode II applied strain energy release rates and stress intensity factors. The strain energy release rates were calculated as explained in Section 3.5 using the equations found in the Appendix.

The asymmetric DCB (ADCB) specimen shown in Figure 4 introduced a significant mode II component to the crack tip loading when equal loads were applied to both adherends resulting in phase angles (Section 3.5) of $\Psi \cong 16^{\circ}$ for steel and $\Psi \cong 18^{\circ}$ for aluminum alloy adherends. This configuration was used for fatigue testing aluminum AA6061-T6 adherends. As mentioned in the introduction, this caused the crack path to be closer to the more highly-strained upper adherend, especially in the fatigue tests at lower crack growth rates.

The reinforced ADCB (rADCB) specimen shown in Figure 5 was used to prevent yielding during the fatigue testing of $2 \mathrm{~mm}$ thick sheets of bare AA5754, coil coated AA5754, etched 
galvanized DP600, and Bonderite coated galvanized DP600. Applying equal loads to the two arms of the rADCB produced a phase angle of $\Psi=11^{\circ}$ for steel and $\Psi=13^{\circ}$ for the aluminum alloys (Section 3.5).

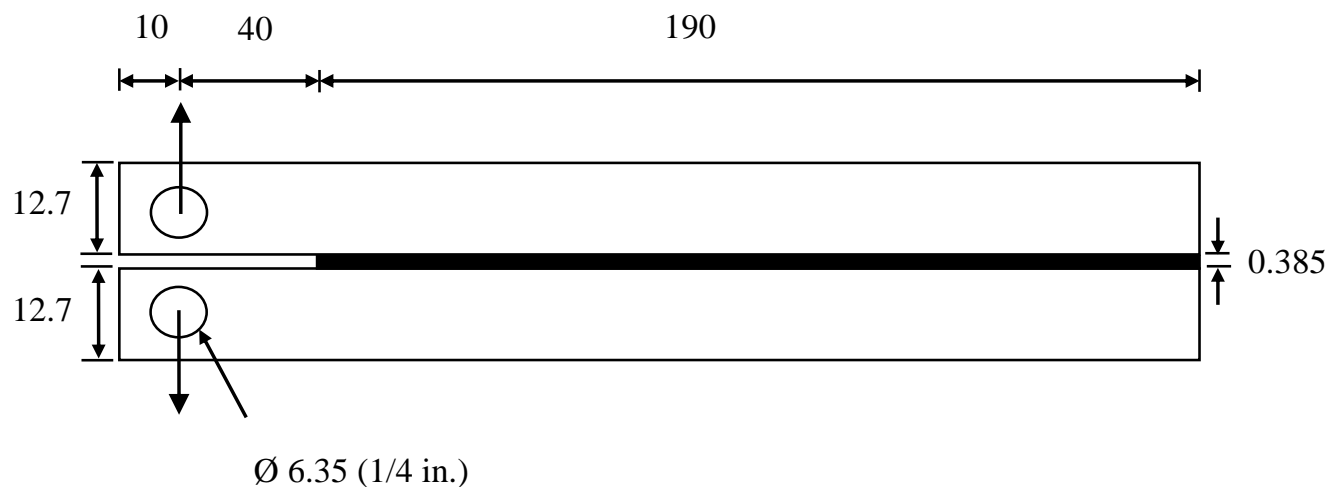

Figure 1 DCB configuration used for AA6061-T6 specimens in fracture and creep. All dimensions in $\mathrm{mm}$, unless stated. 


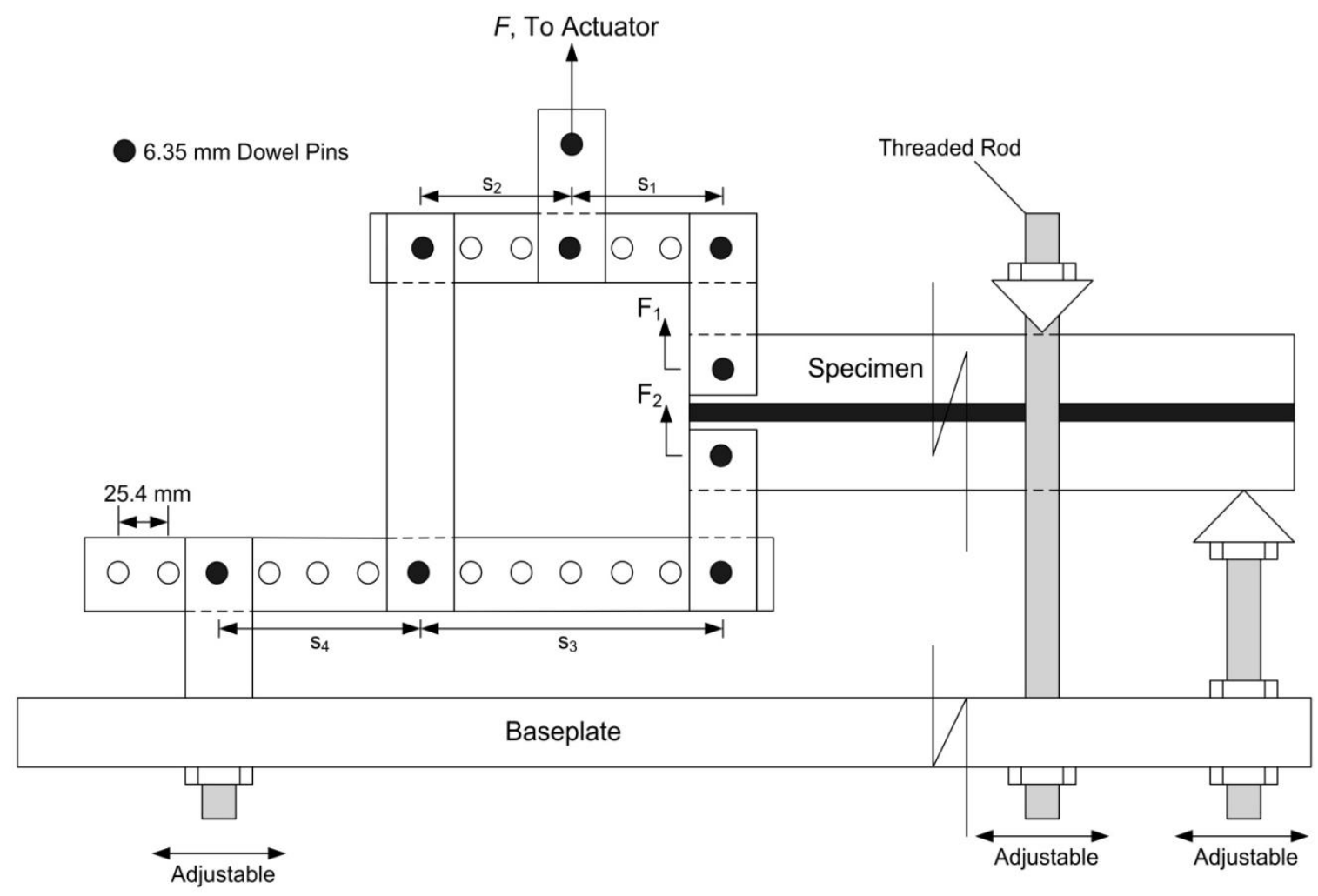

Figure 2 Mixed-mode load jig used with the screw-driven servo-electric load frame in fracture and creep experiments [16]. 


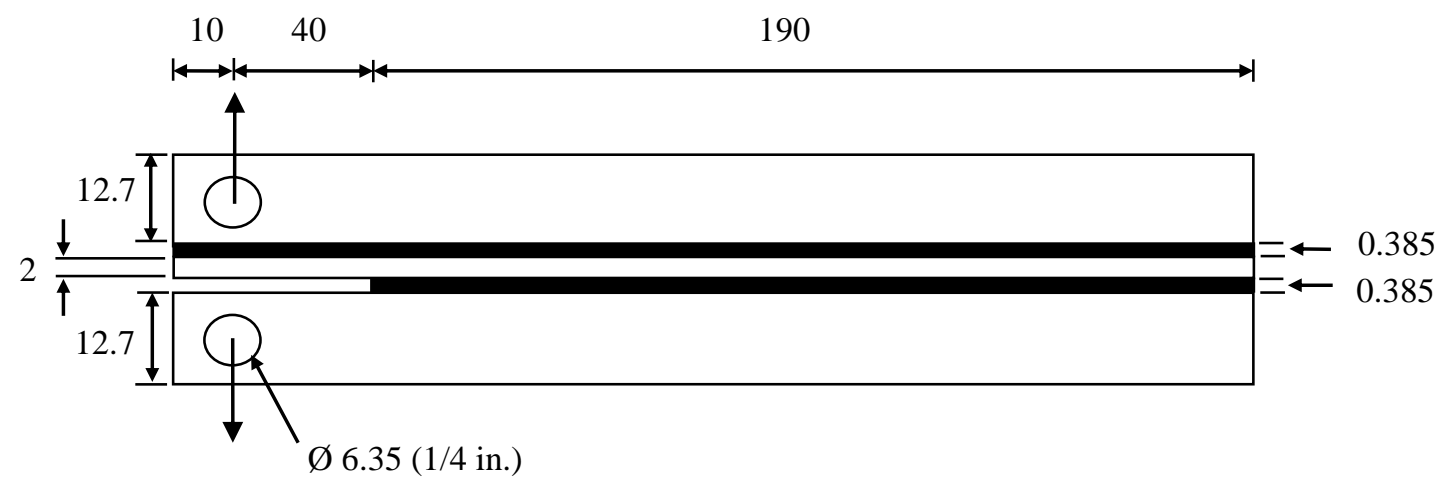

Figure 3 rDCB configuration used for $2 \mathrm{~mm}$ thick hot-dipped galvanized DP600 and coil-coated AA5754 sheet adherends in fracture, fatigue and creep tests. All dimensions in mm, unless stated.

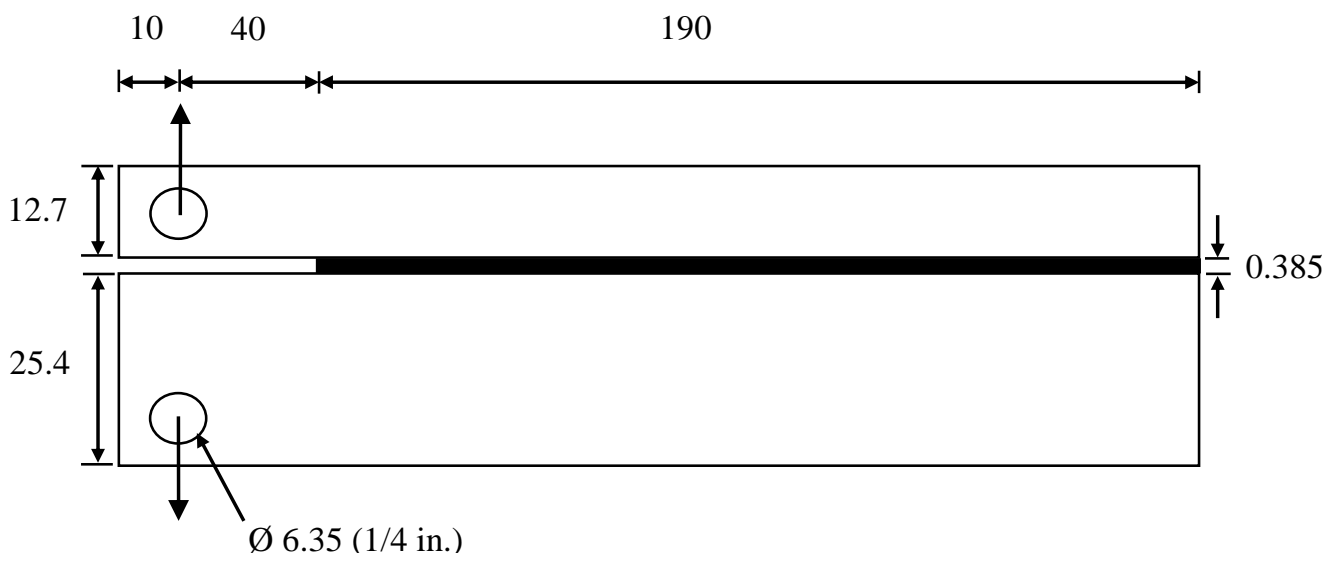

Figure 4 ADCB configuration used for fatigue testing aluminum AA6061-T6 adherends. All dimensions in mm, unless stated. 


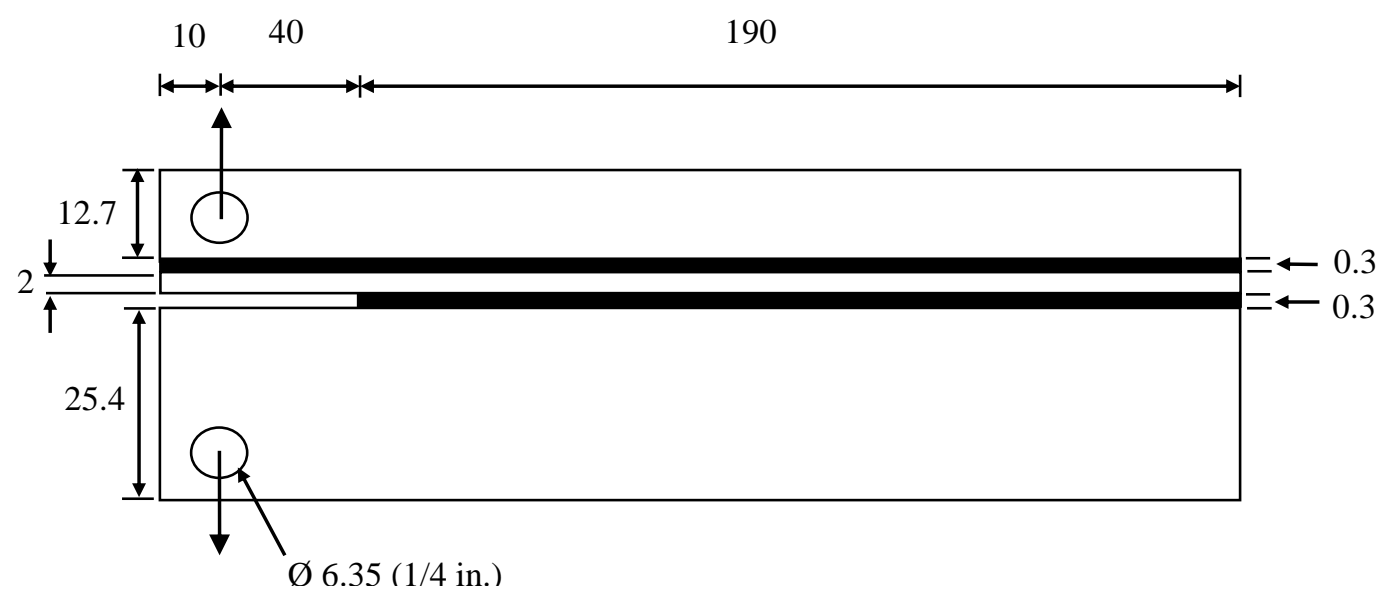

Figure 5 rADCB configuration used for fatigue testing of $2 \mathrm{~mm}$ thick sheets of bare AA5754, coil coated AA5754, etched galvanized DP600, and Bonderite ${ }^{\mathrm{TM}}$ coated galvanized DP600. All dimensions in mm, unless stated.

\subsection{Specimen preparation}

\subsubsection{Steel specimens}

Two types of steel adherends were used: AISI 1018 steel bars and reinforced DP600 hot-dipped galvanized steel sheets. The steel bars were used either as adherends themselves in some DCB specimens used in fatigue, or to reinforce the $2 \mathrm{~mm}$ thick DP600 adherends. The bonding surfaces of the AISI 1018 steel bars were pretreated following the procedures of ref. [7]; i.e. (i) abrasion using an aluminum oxide abrasive pad on an orbital sander to produce a surface roughness, $R_{a}$ of $1.44 \pm 0.15 \mu \mathrm{m}$; then (ii) degreased by wiping with acetone and cheese cloth followed by immersion in acetone for $5 \mathrm{~min}$, then rinsing with ethanol and drying in a clean oven at $55^{\circ} \mathrm{C}$ for $30 \mathrm{~min}$.

The hot-dipped galvanized DP600 sheet was pretreated using either a sulfuric acid-etch or a chemical conversion coating (Bonderite 1402W, Henkel Corporation, Madison Heights, MI, 
USA). The sulphuric acid etched DP600 sheets were first degreased as the steels bars, but were not abraded in order to protect the soft, $10 \mu \mathrm{m}$ thick Zn layer. After degreasing, the DP600 sheets were washed in a dilute detergent bath (FL-70 laboratory detergent, Fisher Scientific, Fair Lawn, NJ, USA) for $5 \mathrm{~min}$ at room temperature, and then rinsed with running de-ionized water for 1 min. They were then etched in a $10 \%$ by volume sulfuric acid solution for $45 \mathrm{~s}$ before being rinsed again in running de-ionized water for $1 \mathrm{~min}$ and dried for $30 \mathrm{~min}$ at $55^{\circ} \mathrm{C}$. Although etching did not change the surface roughness $\left(R_{a}=0.99 \mu \mathrm{m}\right)$, it produced a purer $\mathrm{Zn}$ surface by removing the $\mathrm{Al}$ impurities that have been found to concentrate at the surface of the galvanized layer in DP600 [17]. This was confirmed using energy dispersive x-ray analysis. It has been suggested that the Al impurities can be detrimental to galvanized bonding [18][19][20]. The acid concentration and etch time were selected to remove approximately half of the original $10 \mu \mathrm{m}$ thick $\mathrm{Zn}$ layer, as verified using scanning electron micrographs of cross-sections of the sheet.

The Bonderite $1402 \mathrm{~W}$ pretreatment was applied courtesy of Henkel as follows: The galvanized DP600 sheets were cleaned with Parco Cleaner 1200 (Henkel Technologies, Madison Heights, MI, USA) at $4 \%$ concentration, dried at $60^{\circ} \mathrm{C}$ for $15 \mathrm{~s}$, rinsed in warm water for $10 \mathrm{~s}$, and then air blown dry. Bonderite $1402 \mathrm{~W}$ was then applied at $9 \%$ concentration to achieve a coating weight of $76.4 \mathrm{mg} / \mathrm{m}^{2}$, and flash dried in an infra-red oven. One side was judged to have received a better coating and was marked to indicate the suggested bonding surface.

Both the steel and aluminum specimens (described below) were bonded with a commercial, single-part, heat-cured, highly-toughened structural adhesive designed for automotive applications. The adhesive thickness was controlled using $0.385 \mathrm{~mm}$ steel wires, and a pre-crack was created using a folded aluminum foil at the end of the joints. The specimens were cured in an oven at $180^{\circ} \mathrm{C}$ for at least $30 \mathrm{~min}$ as recommended by the adhesive manufacturer.

\subsubsection{Aluminum specimens}

Aluminum specimens were made using AA6061-T6 aluminum bars either as adherends in fracture and creep tests, or to reinforce AA5754-O sheets in fracture and fatigue experiments. 
The bonding surfaces of the AA6061-T6 bars were degreased following the procedures of ref. [7]: (i) abrasion using an aluminum oxide abrasive pad on an orbital sander to produce an average roughness $R_{a}=1.33$ with standard deviation of $\pm 0.16 \mu \mathrm{m}$; (ii) degreased using acetone and wiped with cheese cloth followed by immersion in acetone for $5 \mathrm{~min}$. The bars were then etched using the P2-etch pretreatment procedures of ASTM D2651 [21]: (i) immersion in $800 \mathrm{~mL}$ of aqueous solution containing $150 \mathrm{~g}$ of ferric sulfate and $200 \mathrm{~mL}$ sulfuric acid (98\%) for $12 \mathrm{~min}$ at $70^{\circ} \mathrm{C}$ with bonding surfaces facing up; (ii) thorough rinse in cold tap water for $3 \mathrm{~min}$; (iii) drying in a clean oven at $55^{\circ} \mathrm{C}$ for $30 \mathrm{~min}$. The $\mathrm{P} 2$-etch was the same pretreatment used on the aluminum adherends in refs. [2] [8] [9][22].

The AA5754-O sheets were either bare or had been coil coated by the manufacturer using a proprietary coil coated pretreatment. The bare AA5754-O sheets were degreased using acetone and wiped with cheese cloth followed by immersion in acetone for $5 \mathrm{~min}$. The coil-coated AA5754-O was received in sealed packaging and was used without further pretreatment.

Previous work with these AA5754-O aluminum sheets showed that the mixed-mode fatigue behavior could be affected by the orientation of the rolling lines [9]. All sheets in this study were prepared with the rolling lines transverse to the direction of crack growth, which was the preferred orientation for improved fatigue performance [9].

\section{Test methods}

\subsection{Fracture tests}

Quasi-static fracture tests were carried out as in ref. [2] using a screw-driven load frame and the load-jig as shown in Figure 2. As mentioned previously, a full range of mode ratios could be generated with a single DCB specimen by adjusting the positions of the link pins [15]. Crack lengths were measured to an accuracy of approximately $20 \mu \mathrm{m}$ using an optical microscope having a field of view of $2 \mathrm{~mm}$ mounted on a micrometer stage. The crack growth was stable and multiple crack growth events and thus multiple $G_{c s}$ values were obtained from a single 
specimen. An overall average $G_{c s}$ was obtained from 13 specimens tested in this manner. In order to obtain the critical strain energy release rate, $G_{c}$, at a given crack length, $a$, the cross-head was advanced at $1.5 \mathrm{~mm} / \mathrm{min}$ until crack growth was observed at a critical load, $P_{c}$, at which point the cross-head was stopped. This measurement was repeated every few mm of crack growth by repeatedly loading and unloading the specimen. Each successive $P_{c}$ measurement corresponded to a higher $G_{c}$ on the rising portion of the R-curve until steady-state was reached at $G_{c s}$ after approximately $10 \mathrm{~mm}$ of initial crack growth for $\psi=0 \sim 27^{\circ}$ [2].

\subsection{Fixed-displacement creep crack growth tests}

Crack growth under conditions of fixed adherend displacement was achieved using either the load jig immediately after the measurement of $G_{c s}$, or using wedge-loaded aluminum or steel DCB specimens. When DCB specimens in the load jig were held at a fixed displacement at $100 \%$ of $G_{c s}$, cracks continued to grow from the fully-developed damage zone even as the load decreased. Crack length and load were recorded after every 20-40 N drop in the load, corresponding to intervals of 1-5 min at the beginning, and every 5-6 h near the end of a $24 \mathrm{~h}$ test, at which point the crack growth had slowed to an arrest threshold of $1 \mathrm{~mm} / 12 \mathrm{~h}\left(2.31 \mathrm{x} 10^{-5}\right.$ $\mathrm{mm} / \mathrm{s})$. This speed is similar to the crack growth rate used to define the fatigue threshold of $10^{-6}$ $\mathrm{mm} /$ cycle at a cyclic frequency of $20 \mathrm{~Hz}\left(2.0 \times 10^{-5} \mathrm{~mm} / \mathrm{s}\right)$ described below. These same procedures were used in ref. [14] to study time-dependent crack growth in two epoxy adhesives.

Figure 6 shows the DCB specimens loaded under a constant displacement using either a $3.1 \mathrm{~mm}$ or $6.1 \mathrm{~mm}$ thick stainless steel wedge following the approach of [14]. The DCB was clamped on its side to a flat surface and the $3.1 \mathrm{~mm}$ wedge was inserted slowly by tapping with a rubber mallet, taking care to ensure that the wedge remained straight so that the crack length was equal across the width of the specimen. The wedges were machined with sharp edges at A and B (Figure 6), which created line contacts with the adherends. Approximately $10 \mathrm{~mm}$ of slow initial crack growth ensured that the creep crack growth test began on the R-curve plateau (steady-state damage zone) for $\psi=0^{\circ}[2]$. The wedge was then slowly inserted further until a small amount 
of additional crack growth occurred, ensuring that $G_{c s}$ had been reached, as verified by calculations using the crack length and the wedge thickness (explained in Section 3.5). This marked the beginning of the subsequent creep tests that were started by slowly tapping the wedge in further and monitoring the crack length until either crack growth arrested or $24 \mathrm{~h}$ had elapsed.

The procedure for loading the specimen by slowly tapping in the wedge created some uncertainty in the $G_{c s}$ measurement, since the wedge may have been inserted slightly further than necessary for crack growth. Typically, a single tap could drive the wedge in a millimeter or two, potentially causing an overestimation in $G$ of approximately $100-200 \mathrm{~J} / \mathrm{m}^{2}$. This created an approximately 2-3\% error depending on the length of the crack.

Following crack arrest, the wedge was inserted further for additional tests. When the $3.1 \mathrm{~mm}$ wedge became too deeply inserted, the thicker $6.1 \mathrm{~mm}$ thick wedge was used to continue the tests. Four or five crack growth sequences could be generated on a single specimen in this way. The crack tip was identified using an optical microscope and the distance from the wedge contact line was measured using a caliper every 1-2 mm of crack growth (time intervals ranging from about 1 min to $6 \mathrm{~h}$ over the course of a $24 \mathrm{~h}$ test). 


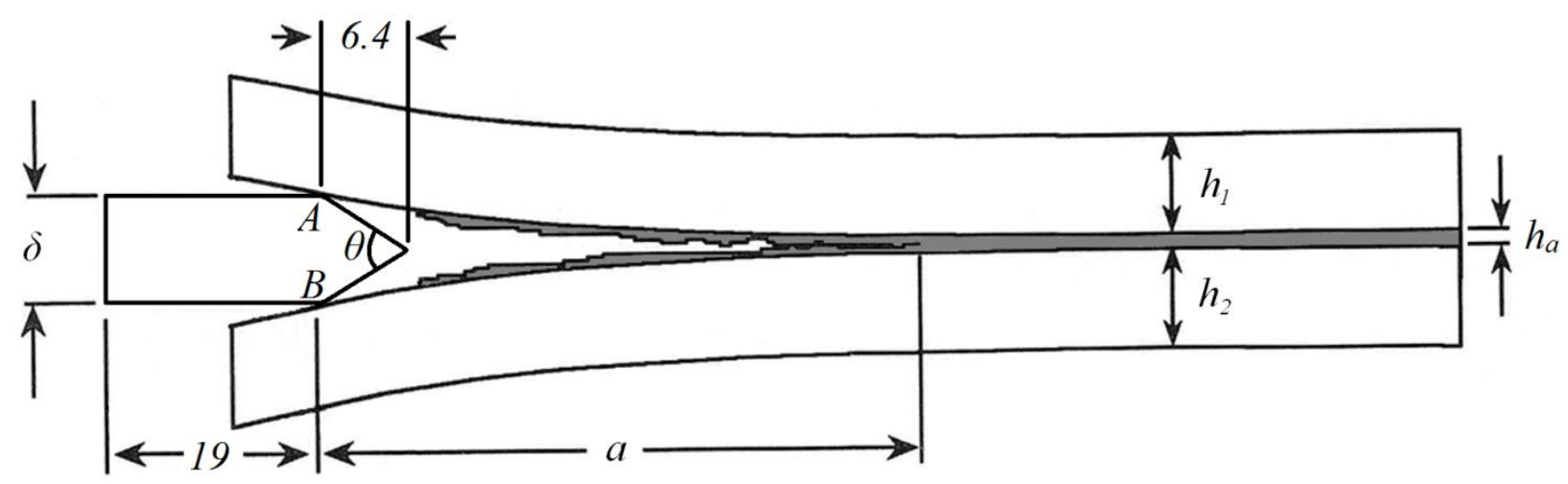

Figure 6 Wedge test on DCB specimen. The displacement induced by the wedge on each arm was $\left(\delta-h_{a}\right) / 2$. $\delta$ was either $3.1 \mathrm{~mm}$ or $6.1 \mathrm{~mm}$. $\theta$ was $28^{\circ}$ for $\delta=3.1 \mathrm{~mm}$ and $50^{\circ}$ for $\delta=6.1 \mathrm{~mm}$. Line contact with DCB arms was made at A and B. The wedge width was the same as the specimen width. All dimensions in mm.

The effect of temperature and humidity during creep crack growth was investigated by placing the wedge specimens in sealed chambers at $25^{\circ} \mathrm{C}$ or $40^{\circ} \mathrm{C}$ containing either a desiccant or saturated salt solutions, giving environments of $25^{\circ} \mathrm{C}-10 \%$ relative humidity $(\mathrm{RH}) ; 40^{\circ} \mathrm{C}-10 \%$ $\mathrm{RH}$ and $40^{\circ} \mathrm{C}-100 \% \mathrm{RH}$ (condensing humidity) [22]. To measure crack growth, the DCB specimens were taken out of the environment chamber for approximately $1 \mathrm{~min}$. A simple heat transfer analysis showed that this resulted in a decrease in the specimen temperature of less than $0.5^{\circ} \mathrm{C}$.

Environmental tests were also conducted on the mode-I aluminum DCB specimens which were held at constant displacement in a servo-hydraulic load frame fitted with an environment chamber maintained at $40^{\circ} \mathrm{C}$ with relative humidities of $10 \%, 95 \%$ and $100 \%$, and at $25^{\circ} \mathrm{C}-0 \%$ RH. In these experiments the specimens remained in the environment chamber at all times and a clip gauge was used to measure the constant specimen opening displacement as a function of the decreasing applied load, from which compliance was calculated to interpolate the crack length. Periodically during a test, the crack length was also measured independently with a CCD camera having a $2 \mathrm{~mm}$ field of view, in order to confirm the compliance calculation. As with the wedge 
test, $10 \mathrm{~mm}$ of slow initial growth ensured that the creep crack growth test started on the R-curve plateau. Testing began on the plateau by increasing the displacement in small discrete amounts until crack growth was observed, which was an indication that $G_{c s}$ was reached, after which the displacement was held fixed for the duration of the creep test (24 h) or until crack arrest. Crack length was measured very frequently, making it possible to accurately record instantaneous crack speeds. Since creep crack growth was only $10-15 \mathrm{~mm}$ in a single $24 \mathrm{~h}$ creep test, $3-5$ repeated creep tests could be performed under identical conditions on a single specimen.

\subsection{Fatigue tests}

Fatigue testing was performed using a servo-hydraulic load frame at $20 \mathrm{~Hz}$ with displacement ratio $D_{\min } / D_{\max }=0.1$ for all specimens. The small phase angle, $\psi=12^{\circ}$, induced by the ADCB specimen caused a shift the crack path toward the more highly-strained adherend and the bonded interface of primary interest [7]. Following the procedures of ref. [2] [7], a clip gauge was used to measure the specimen opening displacement as a function of the applied load, and the unloading joint compliance approach was used to calculate the crack length [23]. Periodically during a test, the crack length was measured independently with a CCD camera having a $2 \mathrm{~mm}$ field of view to confirm the compliance calculation. The unloading joint compliance approach permitted the crack length to be measured very frequently, making it possible to accurately record instantaneous crack speeds [8]. In the displacement-controlled fatigue test, the crack speed, $d a / d N$, gradually decreased to the threshold value of $10^{-6} \mathrm{~mm} /$ cycle as the maximum applied strain energy release rate in a cycle, $G_{\max }$, decreased as the crack length increased. After reaching the threshold, the fatigue specimens were broken in quasi-static fracture as in Section 3.1 , at the same mode ratio as used in the fatigue test.

Table 1 summarizes the tests that were performed with the six adherend/pretreatment combinations and the single adhesive. As explained below, some tests were not necessary because their results could be inferred from other test results. 
Table 1 Tests performed on each type of adhesive joint. Most results for degreased 1018 steel bars came from observations of the opposing adherend surface in reinforced steel sheet specimens. Only some DCBs in fatigue were made entirely of degreased 1018 steel bars.

\begin{tabular}{|c|c|c|c|}
\hline & 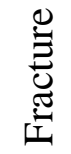 & 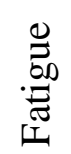 & $\stackrel{巳}{\circlearrowright}$ \\
\hline $\begin{array}{l}\text { Degreased AISI } \\
1018 \text { bar }\end{array}$ & $\mathrm{Y}$ & $\mathrm{Y}$ & $\mathrm{Y}$ \\
\hline $\begin{array}{l}\text { Acid etched } \\
\text { galvanized DP600 } \\
\text { sheet }\end{array}$ & $\mathrm{Y}$ & $\mathrm{Y}$ & $Y$ \\
\hline $\begin{array}{l}\text { Bonderite }^{\mathrm{TM}} \\
\text { galvanized DP600 } \\
\text { sheet }\end{array}$ & $\mathrm{Y}$ & $\mathrm{Y}$ & - \\
\hline $\begin{array}{l}\text { P2 etched AA6061- } \\
\text { T6 bar }\end{array}$ & $\mathrm{Y}$ & $Y$ & $\mathrm{Y}$ \\
\hline $\begin{array}{l}\text { Degreased AA5754- } \\
\text { O sheet }\end{array}$ & $\mathrm{Y}$ & $\mathrm{Y}$ & - \\
\hline $\begin{array}{l}\text { Coil coated } \\
\text { AA5754-O sheet }\end{array}$ & $\mathrm{Y}$ & $\mathrm{Y}$ & - \\
\hline
\end{tabular}

\subsection{Residual adhesive thickness measurement}

The crack path in each adhesive joint was identified by measuring the residual adhesive thickness, $h_{a r}$, using an optical profilometer (Nanovea ST 400, Microphotonics Inc., Irvine, CA, USA). Reference datum points were established on either side of a failure surface by removing a $2 \mathrm{~mm}$ wide strip of the residual adhesive using a mixture of methylene chloride and methyl alcohol (Gluebuster, Kosmic Surf-Pro Inc., Saint Amable, Quebec, Canada) [6]. Twodimensional surface profiles were measured from one datum to the other using a sampling rate of 500 points per mm. The sum of the residual adhesive thicknesses measured on the opposing faces of both adherends was verified to be very close to the nominal bond line thickness of 385 $\mu \mathrm{m}$. 


\subsection{Strain energy release rate and mode ratio calculations}

The applied strain energy release rates, $G$, and mode ratios, $\Psi$, of the adhesive joints were calculated using a beam-on-elastic-foundation model which takes into account the compliance of the adhesive layer [15] [24]. Table 2 summarizes the material properties used in the calculations. The reinforced sheet adherends in the rDCB or $\mathrm{ADCB}$ configurations were modeled as monolithic adherends that were $0.2 \mathrm{~mm}$ thinner than the total thickness of the sheet-adhesivereinforcing bar composite in order to mimic the same bending stiffness [9]. The equations used to calculate $G$ and $\Psi$ for the DCB specimens in the load jig and the ADCB specimens in the fatigue tests are given in the Appendix.

Table 2 Material properties used in calculating the strain energy release rate. The adhesive properties were obtained from the manufacturer.

\begin{tabular}{llll}
\hline & $\begin{array}{l}\text { Elastic } \\
\text { modulus, } E\end{array}$ & $\begin{array}{l}\text { Yield strength, } \\
(\mathrm{GPa})\end{array}$ & $\begin{array}{l}\sigma_{y}(\mathrm{MPa}) \\
\end{array}$ \\
& 1.96 & 40 & $v$ \\
Adhesive & 70 & 255 & 0.45 \\
AA6061-T6 & 70 & 165 & 0.33 \\
AA5754-O & 70 & & 0.33 \\
DP600 & 205 & 370 & 0.33 \\
AISI 1018 & 205 & 370 & 0.33 \\
\hline
\end{tabular}


For the DCB wedge tests, the applied strain energy release rate, $G$, was calculated from the measured crack length, $a$ and the opening displacement, $\delta$. The specimen compliance, $C$, was calculated following the approach of ref. [25] and $P$ was inferred using $C=\delta / P$. This approach was similar to that used in the creep crack growth tests of ref. [14], both being derived from the same beam-on-elastic-foundation model.

This approach was extended in order to calculate $G$ for the wedge-loaded rDCB specimens by assuming that the compliance, $C_{A D C B}$, was the sum of the compliance of the upper, $C_{U}$, and lower, $C_{L}$, beam arms, and that $C_{U}$ and $C_{L}$ equal half the compliance of a corresponding DCB [8]; i.e.

$C_{A D C B}=C_{U}+C_{L}$

where, assuming equal loads on each arm,

$C_{U}=\frac{\delta_{U}}{P}=\frac{4 \lambda_{U}}{2 k}\left(1+2 \lambda_{U} a+2\left(\lambda_{U} a\right)^{2}+\frac{2}{3}\left(\lambda_{U} a\right)^{3}\right)$

$C_{L}=\frac{\delta_{L}}{P}=\frac{4 \lambda_{L}}{2 k}\left(1+2 \lambda_{L} a+2\left(\lambda_{L} a\right)^{2}+\frac{2}{3}\left(\lambda_{L} a\right)^{3}\right)$

$\delta_{A D C B}=\delta_{U}+\delta_{L}$

$P=\frac{\delta_{A D C B}}{C_{A D C B}}$

The constants that reflect the specimen geometry and material are given by

$$
\begin{aligned}
& \lambda_{U}^{4}=\frac{6}{h_{U}{ }^{3} h_{a}} \frac{E_{a}^{\prime}}{E} \\
& \lambda_{L}^{4}=\frac{6}{h_{L}{ }^{3} h_{a}} \frac{E_{a}^{\prime}}{E} \\
& E_{a}^{\prime}=E_{a} /\left(1-v_{a}^{2}\right)
\end{aligned}
$$

where $E$ and $E_{a}$ are the elastic moduli of the adherend and adhesive, respectively, $E_{a}^{\prime}$ is the plane strain adhesive modulus, $v_{a}$ is the adhesive Poisson's ratio, and $h_{a}, h_{L}$, and $h_{U}$ are the thicknesses 
of the adhesive, lower, and upper adherends, respectively. The applied strain energy release rate, $G$, as a function of the opening displacement was then calculated using

$$
G=\frac{\left(\delta / C_{A D C B}\right)^{2}}{2 b} \frac{\partial C_{A D C B}}{\partial a}
$$

where $a$ is the crack length measured from the loading pins and $b$ is the width of the specimen. The inferred load $P$ can be used to find the mode ratio using the approach of ref. [9] that is summarized in the Appendix.

\section{Results and Discussion}

The results for the fracture, creep and fatigue tests are compared and discussed in terms of the influences of: (a) the crack-tip plastic zone size, (b) the test method, (c) the mode ratio, (d) the adherend and pretreatment, and (e) the test environment.

\section{Summary of fracture, creep and fatigue data}

Table 3 summarizes the results of the mode I fracture tests performed in the current study along with several results from earlier work with the same adhesive and adherends. In some cases the reinforced sheet adherend specimen produced a very small phase angle, $\psi$, due to the slight asymmetry of the joint. However, this had a negligible effect on the results since the critical strain energy release rate depends very weakly on $\psi$ in the range $\psi=0$ (mode I) to $30^{\circ}$ [2]. Figure 7 shows the corresponding fracture surfaces of representative AA6061, DP600/AISI 1018 and bare AA5754 specimens.

Table 4 summarizes the 34 creep tests that were performed on the steel and aluminum specimens. All creep tests were under mode-I (or negligible $\psi$ ) conditions except for category 2 which was at $\psi=27^{\circ}$. The tests were grouped in categories 1-10 defined by the particular combination of test method, phase angle, environment and adherend material. The crack length was described well using an exponential function of the time (coefficients in Table 4). These relationships were 
used to calculate the crack average speed, $d a / d t$, plotted in Figure 8. As mentioned in Section 3.2, creep crack growth arrest was defined as being less than or equal to $1 \mathrm{~mm} / 12 \mathrm{~h}\left(2.31 \times 10^{-5}\right.$ $\mathrm{mm} / \mathrm{s})$.

The data for the creep tests at elevated temperature and humidity were obtained using the servohydraulic load frame (LF) and are plotted in Figure 9. Figure 10 and Figure 11 show the failure surfaces for each category of creep tests.

Table 5 summarizes the fatigue $G_{t h}$ and $G$ at the transition from cohesive to interfacial failure for all fatigue specimens tested in the current study as well as those tested in ref. [7] and [9]. Data are presented for the three types of aluminum alloy adherend (P2-etched AA6061-T6 bars, coilcoated AA5754-O sheet and bare AA5754-O sheet) and the two types of steel adherends (acid etched DP600 sheet and Bonderite ${ }^{\mathrm{TM}}$ pretreated DP600 sheet) that were tested in the current study. The steel bars (degreased AISI 1018 and phosphated AISI 1018) were tested in fatigue in a previous study. All fatigue tests were performed in a room-temperature dry (RD) environment in mixed mode $\mathrm{ADCB}$ or $\mathrm{ADCB}$ configurations. For aluminum specimens, crack growth rates are shown in Figure 12, and failure surfaces are shown in Figure 13. For steel specimens, crack growth rates are shown in Figure 14 and Figure 15 and failure surfaces are shown in Figure 16. 
Table 3 Quasi-static fracture tests under mode I or very small mode ratios. DP600 and AA5754O were sheet adherends. $G_{c s}$ is the mean value among the samples and SD is one standard deviation. $N$ is the total number of experiments performed with all specimens. Tests 6,7 and 8 are results taken from ref. [6].

\begin{tabular}{lllllll}
\hline Test & Material & Configuratio & Test method & $\left.\Psi()^{\circ}\right)$ & $\begin{array}{l}G_{c s} \pm S D \\
\left(\mathrm{~J} / \mathrm{m}^{2}\right)\end{array}$ & $N(S)$ \\
\hline 1 & AA6061-T6 P2 etch & DCB & Load Jig & 0 & $3,500 \pm 211$ & $28(3)$ \\
2 & AA6061-T6 P2 etch & DCB & Wedge & 0 & $3,810 \pm 147$ & $7(3)$ \\
3 & DP600 degreased & rDCB & Load Jig & 3 & $3,820 \pm 99$ & $5(1)$ \\
4 & AA5754-O coil coating & rDCB & Load Jig & 4 & $3,680 \pm 77$ & $15(1)$ \\
5 & AA6061-T6 P2 etch & DCB & Load Jig & 27 & $4,180 \pm 196$ & $13(2)$ \\
6 & AA6061-T6 P2 etch & DCB & Load Jig & 0 & $3,220 \pm 210$ & - \\
7 & AA6061-T6 P2 etch & DCB & Load Jig & 27 & $4,160 \pm 260$ & - \\
8 & AA6061-T6 P2 etch & DCB & Load Jig & 48 & $6,650 \pm 460$ & - \\
\hline
\end{tabular}


Table 4 Creep crack growth results. Average $G_{a}$ and $G_{c s}$ grouped in categories defined by the loading, phase angle, environment and adherend material. All specimens were either DCB for aluminum bars, or rDCB for sheet adherends, and all tests started at $100 \% G_{c s}$. Al - P2 etch AA6061-T6 bars, DP - Degreased DP600 sheet reinforced with degreased AISI 1018 steel. RD room-dry $\left(25^{\circ} \mathrm{C} 10 \%-\mathrm{RH}\right)$, HD - hot-dry $\left(40^{\circ} \mathrm{C} 10 \%-\mathrm{RH}\right)$, $\mathrm{HH}$ - hot-humid $\left(40^{\circ} \mathrm{C} 95 \%-\mathrm{RH}\right)$, and HW - hot-wet $\left(40^{\circ} \mathrm{C} 100 \%-\mathrm{RH}\right)$. LJ - load jig; W - wedge loading; LF - servo-hydraulic load frame. The variables $m$ and $b$ are for the curve fits of Figure 8. $N$ is the number of experiments, $(S)$ is the number of specimens. $G_{a} / G_{c s}$ represents the ratio of average $G_{a}$ to average $G_{c s}$.

\begin{tabular}{lllllllll}
\hline $\begin{array}{l}\text { Categ } \\
\text { ory }\end{array}$ & $\begin{array}{l}\text { Mat1/Env/L } \\
\text { oad }\end{array}$ & $\begin{array}{l}\Psi \\
\left({ }^{\circ}\right)\end{array}$ & $\begin{array}{l}G_{c s} \pm \mathrm{SD} \\
\left(\mathrm{J} / \mathrm{m}^{2}\right)\end{array}$ & $\begin{array}{l}G_{a} \pm \mathrm{SD} \\
\left(\mathrm{J} / \mathrm{m}^{2}\right)\end{array}$ & $\begin{array}{l}G_{a} / G_{c s} \\
(\%)\end{array}$ & $\begin{array}{l}N \\
(S)\end{array}$ & $m\left(\mathrm{~m}^{2} / \mathrm{J}\right)$ & $b$ \\
\hline 1 & $\mathrm{Al} / \mathrm{RD} / \mathrm{LJ}$ & 0 & $3630 \pm 70$ & $2980 \pm 107$ & 82 & $3(2)$ & 0.00470 & -19.15 \\
2 & $\mathrm{Al} / \mathrm{RD} / \mathrm{LJ}$ & 27 & $4210 \pm 244$ & $3150 \pm 65$ & 75 & $4(3)$ & 0.00267 & -12.96 \\
3 & $\mathrm{Al} / \mathrm{RD} / \mathrm{W}$ & 0 & $3830 \pm 124$ & $3070 \pm 164$ & 80 & $3(3)$ & - & - \\
4 & $\mathrm{DP} / \mathrm{RD} / \mathrm{LJ}$ & 4 & $3880 \pm 192$ & $3050 \pm 211$ & 79 & $2(1)$ & - & - \\
5 & $\mathrm{Al} / \mathrm{HD} / \mathrm{W}$ & 0 & $3850 \pm 184$ & $2790 \pm 143$ & 73 & $3(3)$ & - & - \\
6 & $\mathrm{Al} / \mathrm{HW} / \mathrm{W}$ & 0 & $3680 \pm 226$ & $1140 \pm 1073$ & 31 & $4(4)$ & - & - \\
7 & $\mathrm{Al} / \mathrm{RD} / \mathrm{LF}$ & 0 & $3910 \pm 93$ & $3100 \pm 31$ & 79 & $3(1)$ & 0.00299 & -14.1 \\
8 & $\mathrm{Al} / \mathrm{HD} / \mathrm{LF}$ & 0 & $3790 \pm 109$ & $3090 \pm 85$ & 82 & $4(1)$ & 0.00324 & -14.7 \\
9 & $\mathrm{Al} / \mathrm{HH} / \mathrm{LF}$ & 0 & $3630 \pm 144$ & $2570 \pm 107$ & 71 & $5(1)$ & 0.00210 & -9.86 \\
10 & $\mathrm{Al} / \mathrm{HW} / \mathrm{LF}$ & 0 & $2630 \pm 132$ & $1860 \pm 61$ & 71 & $3(1)$ & 0.00239 & -8.86 \\
\hline
\end{tabular}


Table 5 Fatigue test results for steel and aluminum adherends. $\psi=13^{\circ}$ for all aluminum specimens and $\psi=11^{\circ}$ for all steel specimens. Results for AISI steel from [9] and [7] as indicated. The effect of mode ratio on $G_{t h}$ was negligible below $27^{\circ}$ [7]. $S$ indicates number of specimens. Each specimen was used to perform one experiment.

\begin{tabular}{|c|c|c|c|c|c|}
\hline Adherend & $\begin{array}{l}G \text { at } \\
\text { transition } \\
\text { from } \\
\text { cohesive to } \\
\text { interface } \\
\left(\mathrm{J} / \mathrm{m}^{2}\right)\end{array}$ & $G_{t h}\left(\mathrm{~J} / \mathrm{m}^{2}\right)$ & $\Psi\left(\left(^{\circ}\right)\right.$ & $S$ & Failure Surface \\
\hline $\begin{array}{l}\text { P2-etched AA6061- } \\
\text { T6 }\end{array}$ & - & $136 \pm 3$ & 18 & 2 & Cohesive \\
\hline $\begin{array}{l}\text { P2-etched AA6061- } \\
\text { T6 [9] }\end{array}$ & - & $157 \pm 9$ & 18 & 3 & Cohesive \\
\hline $\begin{array}{l}\text { Degreased } \\
\text { AA5754-O }\end{array}$ & $212 \pm 10$ & $63 \pm 10$ & 13 & 2 & Cohesive to interfacial \\
\hline $\begin{array}{l}\text { Coil coated } \\
\text { AA5754-O }\end{array}$ & - & $36 \pm 1$ & 13 & 2 & Interfacial \\
\hline Acid etched DP600 & $194 \pm 36$ & $59 \pm 16$ & 11 & 3 & Cohesive to interfacial \\
\hline Bonderite DP600 & $332 \pm 28$ & $93 \pm 17$ & 11 & 3 & Cohesive to interfacial \\
\hline $\begin{array}{l}\text { Degreased } \\
\text { AISI } 1018 \text { [7] }\end{array}$ & - & $40 \pm 10$ & 27 & 4 & Interfacial \\
\hline $\begin{array}{l}\text { Zn-phosphated } \\
\text { AISI 1018 [7] }\end{array}$ & - & $180 \pm 12$ & 16 & 4 & Cohesive \\
\hline
\end{tabular}




\subsection{Comparison of Crack Paths in Fracture, Creep and Fatigue - Effect of crack-tip plastic zone size}

Table 6 compares the failure surfaces observed in quasi-static fracture, fatigue and creep fracture for six adherend/pretreatment combinations. It is seen that, for a given adherend, cohesive failure (within the adhesive layer) in fracture and creep can become interfacial or near-interfacial in mixed-mode, near-threshold fatigue. The indicated figures show the fracture surfaces for both the rising part of the R-curve and the steady-state plateau. The indicated fatigue failure surfaces are shown for the range of applied $G$ from the high value at start of the test to the threshold. The creep fracture surfaces are similarly shown from $G_{c s}$ at the beginning of the test to crack arrest at $G_{a}$. It is noted that the phase angles were all very small and effectively the same, and would be expected to produce fracture energies approximately equal to the mode I value. Even at the extreme value of $\psi=27^{\circ}$ in Table $6, G_{c s}$ was within $20 \%$ of $G_{I c s}\left(\psi=27^{\circ} G_{c s}=4,180 \mathrm{~J} / \mathrm{m}^{2}\right.$ (test 5 , Table 3), $G_{c s}=3,500 \mathrm{~J} / \mathrm{m}^{2}$ under mode I (test 1, Table 3)). As mentioned previously, the main reason for using a small phase angle in adhesive joint testing was to steer the average crack path toward the adherend of interest. Similar to fracture, the effect of mode ratio on the fatigue threshold is insignificant between $\psi=0^{\circ} \sim 24^{\circ}$ [7]. The results of Table 6 are discussed in detail below. 
Table 6 Tests performed on each type of adhesive joint. Fatigue and creep tests done with continuously decreasing applied $G$ to approach fatigue threshold $\left(G_{t h}\right)$ or crack arrest $\left(G_{a}\right)$, respectively. RD - room temperature dry; $\mathrm{HD}$ - hot, dry; $\mathrm{HH}$ - hot, humid; HW - hot, wet.

\begin{tabular}{|c|c|c|c|}
\hline & $\begin{array}{l}\text { Quasi-static } \\
\text { Fracture }\end{array}$ & $\begin{array}{l}\text { Fatigue } \\
\text { Approaching } G_{t h}\end{array}$ & $\begin{array}{l}\text { Creep } \\
\text { Approaching } G_{a}\end{array}$ \\
\hline $\begin{array}{l}\text { Degreased AISI } \\
1018 \text { bar }\end{array}$ & $\begin{array}{l}\psi=0^{\circ} \\
\text { Cohesive } \\
\text { (Figure } 7 \mathrm{~b})\end{array}$ & $\begin{array}{l}\psi=12^{\circ} \\
\text { Interfacial for all G } \\
\text { (ref. [7]) }\end{array}$ & $\begin{array}{l}\psi=0^{\circ}, \mathrm{RD} \\
\text { Cohesive for all } G \\
\text { (Figure 10c) }\end{array}$ \\
\hline $\begin{array}{l}\text { Acid etched } \\
\text { galvanized DP600 } \\
\text { sheet }\end{array}$ & $\begin{array}{l}\psi=0^{\circ} \\
\text { Cohesive } \\
\text { (Figure 7b) }\end{array}$ & $\begin{array}{l}\psi=12^{\circ} \\
\text { Cohesive becoming } \\
\text { interfacial near } G_{t h} \\
\text { (Figure 16a) }\end{array}$ & $\begin{array}{l}\psi=0^{\circ}, \mathrm{RD} \\
\text { Cohesive for all } G \\
\text { (Figure 10c) }\end{array}$ \\
\hline $\begin{array}{l}\text { Bonderite } \\
\text { galvanized DP600 } \\
\text { sheet }\end{array}$ & $\begin{array}{l}\psi=12^{\circ} \\
\text { Cohesive (after } \\
\text { fatigue test) }\end{array}$ & $\begin{array}{l}\psi=12^{\circ} \\
\text { Cohesive becoming } \\
\text { interfacial near } G_{t h} \\
\text { (Figure } 16 \mathrm{c}, \mathrm{d} \text { ) }\end{array}$ & - \\
\hline $\begin{array}{l}\text { P2 etched AA6061- } \\
\text { T6 bar }\end{array}$ & $\begin{array}{l}\psi=0^{\circ} \text { and } 27^{\circ} \\
\text { Cohesive } \\
\text { (Figure 7a) }\end{array}$ & $\begin{array}{l}\psi=12^{\circ} \\
\text { Cohesive becoming } \\
\text { nearly interfacial } \\
\text { near } G_{t h} \\
\text { (Figure 13a) }\end{array}$ & $\begin{array}{l}\psi=0^{\circ}, 27^{\circ} \mathrm{RD} \\
\text { Cohesive for all } G \\
\psi=0^{\circ}, \mathrm{HD} \\
\text { Cohesive for all } G \\
\psi=0^{\circ}, \mathrm{HH} \\
\text { Cohesive for all } G \\
\psi=0^{\circ} \mathrm{HW} \\
\text { Interfacial for all } G \\
\text { (Figure } 11 \mathrm{a}-\mathrm{d} \text { ) }\end{array}$ \\
\hline $\begin{array}{l}\text { Degreased } \\
\text { AA5754-O sheet }\end{array}$ & $\begin{array}{l}\psi=12^{\circ} \\
\text { Cohesive (after } \\
\text { fatigue test) } \\
\text { (Figure } 13 \mathrm{~b}, \mathrm{c} \text { ) }\end{array}$ & $\begin{array}{l}\psi=12^{\circ} \\
\text { Cohesive becoming } \\
\text { interfacial near } \mathrm{G}_{\mathrm{th}} \\
(\text { Figure } 13 \mathrm{~b}, \mathrm{c})\end{array}$ & - \\
\hline $\begin{array}{l}\text { Coil coated } \\
\text { AA5754-O sheet }\end{array}$ & $\begin{array}{l}\psi=12^{\circ} \\
\text { Cohesive (after } \\
\text { fatigue test) } \\
\text { (Figure 13d) } \\
\psi=0^{\circ} \\
\text { Cohesive } \\
\text { (Figure 7c) }\end{array}$ & $\begin{array}{l}\psi=12^{\circ} \\
\text { Interfacial } \\
\text { (Figure 13d) }\end{array}$ & - \\
\hline
\end{tabular}




\subsubsection{Fatigue}

A previous study on mixed-mode fatigue with the same adhesive demonstrated that the crack path became progressively closer to the more highly-strained adherend as the applied $G$, and hence the crack growth rate, decreased to the threshold [7][12][22]. This shift in the crack path was explained using finite element modeling as being due to a decrease in the crack-tip plastic zone size [22]. It was hypothesized that the distance between the crack tip and the more highlystrained adherend was controlled by the size of the plastic zone, so that it became smallest at the fatigue threshold. This progressive shift of the crack tip to the interface as $G_{t h}$ is approached, tends to concentrate stresses at the interface and promote interfacial failure as shown in Figure 13a-c and Figure 16a,c,d. Consequently, the crack paths and $G_{t h}$ values became more sensitive to the effect of pretreatment and adherend material compared to fracture or creep. These same figures also show the quasi-static fracture surfaces generated when the fatigue specimens were fractured slowly at the same mode ratio after reaching the fatigue threshold. In all cases, interfacial failure in fatigue near the threshold caused by the small plastic zone, became cohesive when subsequently fractured using quasi-static loading, because the much greater applied G produced a much larger plastic zone, as explained in refs. [7], [12], [22]. Even when the specimens remained cohesive but near-interfacial in fatigue near the threshold (e.g. P2-etched AA6061-T6), the residual adhesive on the fatigue failure surface was very much thinner than that observed in fracture or creep.

\subsubsection{Creep crack growth}

The crack paths in the mode-I and mixed-mode creep specimens tested in room-dry conditions, shown in Figure 10 and Figure 11, were similar to those noted in quasi-static fracture specimens tested in room-dry conditions as shown in Figure 7. For example, Figure 17 shows the profilometer trace along the centerline of the upper adherend failure surface from $G_{c S}$ to $G_{a}$ for one of the P2-etched AA6061-T6 specimens in mode-I creep tested with the load jig in room-dry conditions (category 1 Table 4). Although the residual adhesive thickness also oscillated across the width of the specimen, on average the crack remained near the mid-plane of the adhesive 
layer as depicted in Figure 17 on the centerline. Measurements on two mode-I creep specimens (category 1, Table 4 and category 7, Table 4), gave an average surface roughness, $R_{a}$, of $18 \pm 1.1$ $\mu \mathrm{m}$, and an average thickness of the residual adhesive, $h_{a r}$, of $193 \pm 9 \mu \mathrm{m}$, which was about half the total adhesive thickness, $h_{a}$ of $387 \mu \mathrm{m}$. These observations are very similar to the corresponding values obtained from mode-I fracture specimens, where $R_{a}$ was $19 \mu \mathrm{m}, h_{a r}$ was $190 \mu \mathrm{m}$ and $h_{a}$ was 385 [6].

Figure 18 shows the profilometer trace along the centerline of the failure surface of the more highly-strained adherend for a mixed-mode creep crack growth P2-etched AA6061-T6 specimen tested with the load jig in room temperature-dry conditions (category 2 Table 4). On two traces (once each on two specimens), $R_{a}$ was $20 \pm 1.2 \mu \mathrm{m}, h_{a r}$ was $137 \pm 1.5 \mu \mathrm{m}$, and $h_{a}$ was $396 \pm 6.7$ $\mu \mathrm{m}$, indicating that the crack path had shifted approximately $50 \mu \mathrm{m}$ from the mid-plane toward the more highly-strained adherend, as expected. For similar fracture specimens, this deviation was only $20 \mu \mathrm{m}\left(h_{a r}\right.$ was $\left.170 \mu \mathrm{m}\right)$ [6]. This additional shift in the average crack path toward the more highly-strained adherend in creep is consistent with the smaller applied strain energy release rate and hence plastic zone in these creep tests compared with the fracture tests. For example, when creep crack growth had stopped, $G_{a}$ was approximately $3,000 \mathrm{~J} / \mathrm{m}^{2}$ in the mixedmode creep test of Figure 18, while the steady-state fracture energy $G_{c s}$ was $4,200 \mathrm{~J} / \mathrm{m}^{2}$ in the comparable fracture test [6].

\subsection{Creep tests}

No effect of test method was observed in mode-I room temperature-dry (RD) creep. $G_{a}$ from the servo-electric load frame (category 1, Table 4), wedge (category 3, Table 4) and servo-hydraulic load frame (category 7) results were $2,980 \mathrm{~J} / \mathrm{m}^{2}, 3,070 \mathrm{~J} / \mathrm{m}^{2}$, and $3,100 \mathrm{~J} / \mathrm{m}^{2}$, respectively. These differences were statistically insignificant (paired t-tests, 95\% confidence). Similarly, the differences in $G_{a}$ values between mode-I creep at $40^{\circ} \mathrm{C}-10 \% \mathrm{RH}$ (HD) for the wedge test (category 5, Table 4) and the servo-hydraulic load frame test (category 8, Table 4) were statistically insignificant (t-test, $95 \%$ confidence). 
$G_{a} / G_{c s}$ was $80 \%$ for both DP600 sheet (category 4, Table 4) and AA6061 bar (categories 1 and 3, Table 4) adherend specimens tested in mode-I RD creep since the crack paths were always cohesive, regardless of whether the loading was applied using the load jig (category 1, Table 4) or wedge (categories 3 and 4, Table 4).

The phase angle had no effect on $G_{a}$ (t-test, $95 \%$ confidence), as seen by comparing mode-I $G_{a}$ (category 1, Table 4 ) and mixed-mode $G_{a}\left(\psi=27^{\circ}\right.$, category 2 , Table 4$)$. The mixed-mode fracture $G_{c s}\left(\psi=27^{\circ}\right.$, category 2 , Table 4$)$, however, was $14 \%$ higher than that of mode-I (category 1, Table 4), a statistically significant difference (t-test, 95\% confidence). This indicates that the gains in the fracture toughness of the adhesive with increasing phase angle were slightly less pronounced at the arrest of creep crack growth. As expected then, the average creep crack growth from $G_{c s}$ to $G_{a}$ was $25.6 \pm 7.6 \mathrm{~mm}$ under mixed-mode loading, but only 8.37 $\pm 3.5 \mathrm{~mm}$ for mode I loading. Because these were displacement controlled tests, $G$ decreased with crack growth, and a larger crack growth was required to accommodate the larger drop in $G$ to reach $G_{a}$ under mixed-mode loading. As shown in Figure 8, this caused a shallower slope for the mixed-mode creep crack growth curve compared to that in mode I

These results are consistent with those of ref. [14], where only small differences were measured in $G_{a} / G_{c s}$ among creep tests between $\Psi=0^{\circ} \sim 40^{\circ}$. However, at $\psi=80^{\circ}, G_{a} / G_{c s}$ was significantly higher than in mode I creep tests [14]. As discussed in Section 4.1, increasing mode ratio also caused the crack path to become closer to the more highly strained adherend in both the fracture and creep specimens.

The crack path in mode-I creep under dry conditions was cohesive for the AA6061 (Figure 10(a)), the acid-etched DP600 and the AISI 1018 steel (Figure 10(c)) specimens, just as it was under quasi-static fracture, with a minor variation in $G_{c s}$. Therefore, the adherend had no effect and, as expected, the differences in average $G_{a}$ for the mode-I creep tests were statistically insignificant (t-test, $95 \%$ confidence); i.e. AA6061 $G_{a}=2,980 \mathrm{~J} / \mathrm{m}^{2}$ (Table 4 category 1) and DP600 $G_{a}=3,050 \mathrm{~J} / \mathrm{m}^{2}$ (Table 4 category 4 ). 


\subsubsection{Effect of environment on the P2-etched AA6061-T6 system}

In dry conditions, the effect of temperature on creep was insignificant. All room temperature-dry (RD) and $40^{\circ} \mathrm{C}-10 \% \mathrm{RH}$ hot-dry (HD) creep test specimens failed within the adhesive layer as illustrated in Figure 10(a) for the aluminum adherends. Similarly, $G_{a}$ for this system was independent of temperature in the mode-I wedge creep tests: $G_{a}=2,790 \mathrm{~J} / \mathrm{m}^{2}$ in the hot-dry (HD) environment (Table 4 category 5), which was statistically indistinguishable (t-test, 95\% confidence) from $G_{a}=3070 \mathrm{~J} / \mathrm{m}^{2}$ measured in the room-temperature dry (RD) environment (Table 4 category 3). Since $G_{c s}$ was also unaffected by temperature over this range in the system, $G_{a} / G_{c s}$ was $73 \%$ in the HD environment and $80 \%$ in the RD environment, a difference which was also statistically insignificant (t-test, 95\% confidence). These results are consistent with those of ref. [14] which found that temperature had no effect on the creep crack growth of a different epoxy adhesive in the temperature range $25-80{ }^{\circ} \mathrm{C}$.

In contrast, the moisture in the $40^{\circ} \mathrm{C}, 100 \% \mathrm{RH}$ ( $\mathrm{HW}$; condensing humidity) environment (wedge test, Table 4 category 6) severely degraded the creep cracking performance of the P2-etched AA6061-T6 system, and resulted in a completely interfacial failure (Figure 10 (b)) with low average values of $G_{a}\left(1,140 \mathrm{~J} / \mathrm{m}^{2}\right)$ and $G_{a} / G_{c s}(31 \%)$. Unlike the slow crack growth that occurred over $24 \mathrm{~h}$ during the RD mode-I wedge creep test, the crack growth was much faster under the HW condition, rupturing the specimen within $5 \mathrm{~h}$. Because of this, it was not possible to obtain sufficient crack speed data to obtain a crack growth curve. This is a well-known result, and explains why hot-wet wedge tests have a long history as a means of assessing the relative durability of adhesive joints.

The servo-hydraulic load frame was also used to perform creep crack growth tests in various environments (Table 4 categories 7 to 10) on the P2-etched AA6061-T6 system. In addition to the hot-dry (HD) and hot-wet (HW, condensing humidity) tests done with the wedge, the load frame was used to test a $40^{\circ} \mathrm{C}, 95 \% \mathrm{RH}(\mathrm{HH})$ environment (Table 4 category 9), in which water condensation was eliminated by using a slightly lower relative humidity. As with the wedge tests, Figure 11 and Table 4 show that the failure surfaces and $G_{a}$ were similar in roomtemperature dry (RD) (Table 4 category 7) and hot-dry (HD) conditions (Table 4 category 8). 
However, Figure 9 shows that the crack speed was increased for a given applied $G$ due to the higher temperature used in the HD test compared to the RD test. The effect of moisture is evident in Figure 9 and Table 4 by comparing the three $40^{\circ} \mathrm{C}$ load frame tests: HD (dry), $\mathrm{HH}$ (95\% $\mathrm{RH})$ and $\mathrm{HW}(100 \% \mathrm{RH})$. It is seen that the crack speed increased and $G_{a}$ decreased as the amount of moisture increased.

In the hot-humid ( $\mathrm{HH} ; 95 \% \mathrm{RH}$ ) environment, the crack was cohesive near $G_{a}$, but in the condensing hot-wet (HW; 100\% RH) environment it was interfacial near arrest (Figure 11). This significant effect of the presence of liquid water at the crack tip on crack path has also been previously noted for adhesive joints loaded in mixed-mode fatigue, where it was accompanied by a significant decrease in $G_{t h}$ [22]. This was attributed to moisture diffusion ahead of the crack tip being faster than the crack growth rate near the threshold, thus hydrating the aluminum oxide and weakening the interface, causing interfacial failure [22]. This is similar to data reported for fracture tests in humidity-controlled environments using steel or aluminum adherends at a range of loading speeds [26]. Interfacial failure was only observed at low crack growth rates when moisture could diffuse ahead of the crack tip [26]. Therefore, the present experiments show that, despite the dissimilar strain energy release rates and damage zone sizes in creep and fatigue testing, condensed moisture caused interfacial failure in creep crack growth just as it did in mixed-mode near-threshold fatigue because of the low crack speeds.

\subsection{Fracture tests}

The mode-I $G_{c s}$ measured in this study using the load jig and the P2-etched AA6061 adherends was $3,500 \mathrm{~J} / \mathrm{m}^{2}$ (test 1 , Table 3 ) which compares well with the $3,220 \mathrm{~J} / \mathrm{m}^{2}$ reported in ref. [6] for the same adherends and adhesive (shown as test 6, Table 3). The measured $G_{c s}$ using the wedge test (test 2, Table 3) was slightly higher; i.e. $3,800 \mathrm{~J} / \mathrm{m}^{2}$ (difference significant; t-test, $95 \%$ confidence). As explained in Section 3.2 this was attributed to the small overloading that can result from the 1-2 mm increments in crack length each time the wedge was tapped. In a similar manner, $G_{c s}$ was also overestimated using the servo-hydraulic load frame (categories 7, 8 and 9 
in Table 4) by $100-200 \mathrm{~J} / \mathrm{m}^{2}$. With the servo-hydraulic load frame, $G_{c s}$ was measured by increasing the opening displacement in small increments of $0.1-0.3 \mathrm{~mm}$ until the crack began to grow. The measurement of $G_{c s}$ with the screw-driven servo-electric load frame (with the load-jig) was more accurate, because the displacement was increased continuously and at a sufficiently slow speed that it could be stopped the instant that crack growth was observed.

The steady-state fracture energy, $G_{c s}$, of the various adhesive joints was expected to be independent of the adherend, because all of the fracture surfaces were cohesive within the adhesive layer (Figure 7). This was consistent with previous studies using the same adhesive with aluminum and steel adherends that also found an insignificant effect of adherend elastic modulus on $G_{c s}$ [16]. However, the data of Table 3 showed a small, but statistically significant (pair-wise t-test, 95\% confidence) difference among the mode-I $G_{c s}$ values among P2-etched AA6061 (3500 J/m², test 1$)$, sulfuric acid etched DP600 (3810 J/m², test 3$)$, and bare AA5754 $\left(3680 \mathrm{~J} / \mathrm{m}^{2}\right.$, test 4$)$ specimens. These small differences were probably due to specimen to specimen variability, and not solely due to the effect of adherend.

\subsection{Fatigue tests}

Table 5 summarizes the fatigue results in both the current and previous fatigue studies [7] and [9]. The present fatigue results are consistent with results reported in the literature for the same adhesive and pretreatment. For example, mixed-mode fatigue of P2-etched AA6061 specimens resulted in $G_{t h}=157 \mathrm{~J} / \mathrm{m}^{2}$ in ref. [9] while $G_{t h}=136 \mathrm{~J} / \mathrm{m}^{2}$ in the current study.

It is noted that creep crack growth in the P2-etched AA6061 specimens under room temperaturedry conditions arrested at much higher values of the applied strain energy release rate than the threshold value in fatigue; e.g. mixed-mode $G_{a}=3,000 \mathrm{~J} / \mathrm{m}^{2}$ and $G_{t h}=136 \mathrm{~J} / \mathrm{m}^{2}$. This illustrates that cyclic loading was much more damaging than the sustained loading imposed during these fixed-displacement creep tests under dry conditions. 
As expected, Table 5 shows that the $G_{t h}$ of specimens that failed interfacially was lower than that for specimens that failed cohesively. In three types of specimens, crack paths started cohesively, but then became interfacial at the noted value as $G$ decreased toward $G_{t h}$. This is consistent with the progressive shift toward the more highly-strained adherend that is made possible by the decreasing $G$ causing a small plastic zone, as discussed in Sections 4.1 and 4.2.

Figure 12 shows the expected trend that fatigue strength decreased when cracks grew interfacially. For example, interfacial crack growth for coil-coated AA5754 (failure surface in Figure 13 (d)) was much faster and the threshold was lower than for P2-etched AA6061, (Figure 13 (a)) specimens that failed cohesively within the adhesive layer.

The behavior of degreased AA5754 in Figure 12 illustrates an interesting phenomenon that occurred when the crack path was initially cohesive, but became interfacial as $G$ decreased toward the threshold (failure surface of Figure 13(b)). The curve in the cohesive regime ( $G>$ $212 \mathrm{~J} / \mathrm{m}^{2}$, left of horizontally striped triangle in Figure 13 (b), (c)) coincided with the curve for the fully cohesive specimen of P2-etched AA6061, but the crack growth accelerated as soon as the crack became interfacial at $G=212 \mathrm{~J} / \mathrm{m}^{2}$ (Table 5), creating the cusp in Figure 12. The crack speed then decelerated once again as the crack grew along the interface until it reached $G_{t h}$. As explained below, the abruptness of this change from a decelerating to an accelerating crack coincided with the abruptness of the transition from cohesive to adhesive crack growth.

Similar behavior is seen in Figure 14 and Figure 15, where the abrupt cusps in the crack growth curves correspond to the relatively abrupt transitions from cohesive crack growth to interfacial crack growth shown in Figure 16. After decelerating cohesively, the crack accelerated as parts of the crack front reached the interface, and then decelerated once again as crack growth proceeded interfacially. Table 5 gives the values of $\mathrm{G}$ at which the transition occurred; i.e. the locations of the cusps in Figure 14 and Figure 15.

The fatigue crack growth curves of ref. [7] at a high phase angle $\left(\psi=50^{\circ}\right)$ for degreased steel and Zn-phosphated steel showed a similar but less pronounced transition as the crack became very 
close to the interface as the applied $G$ approached $G_{t h}$. At this phase angle, the driving force for the crack to shift to the more highly-strained adherend was large. 

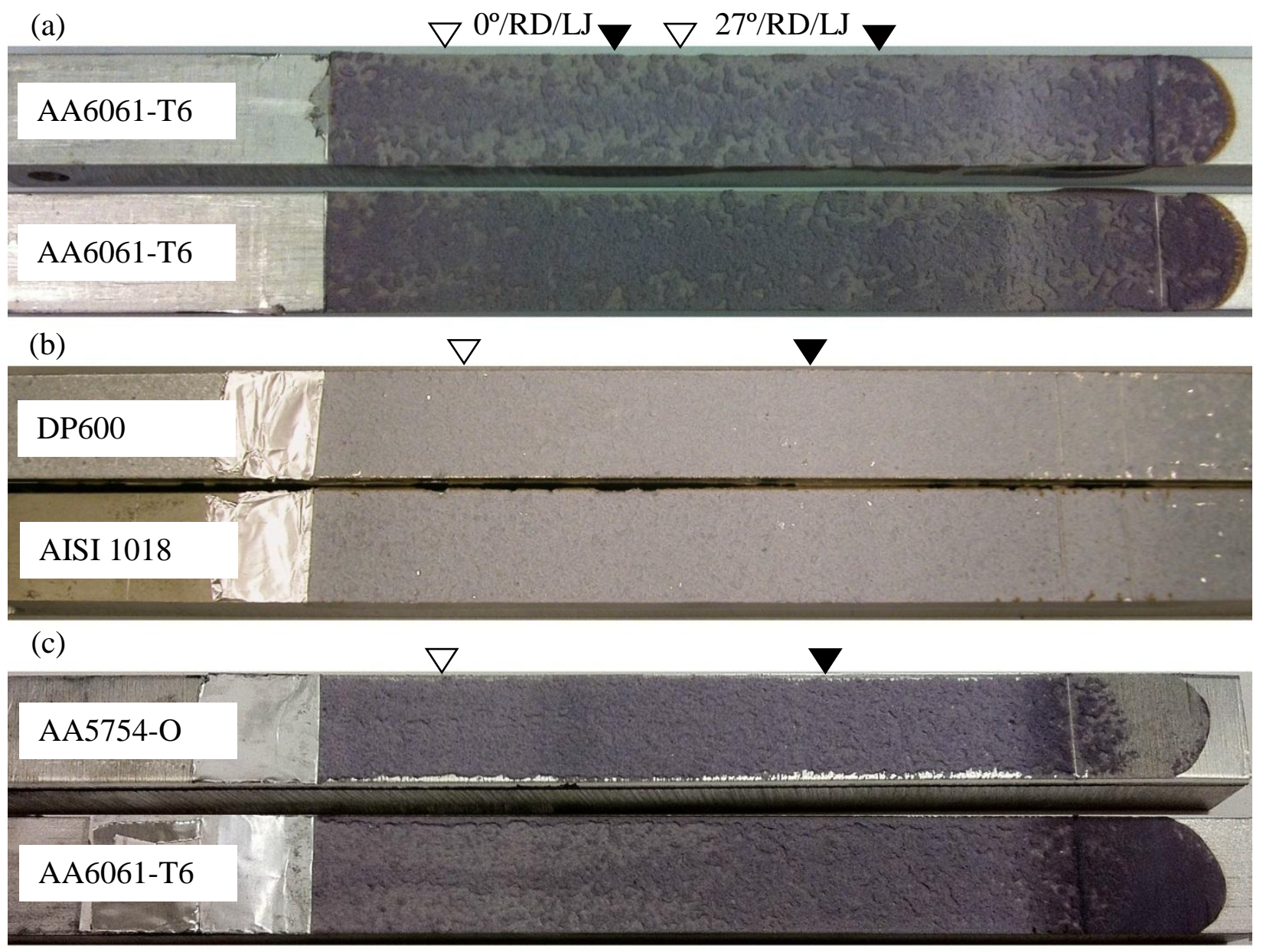

Figure 7 Mode I quasi-static fracture surfaces of: (a) P2 etched AA6061-T6, (b) sulphuric acid etched DP600 $\left(\psi=3^{\circ}\right)$ bonded to AISI steel bar and (c) coil coated AA5754-O $\left(\psi=4^{\circ}\right)$. Steadystate $G_{c s}$ data were collected between the white and black triangles. 


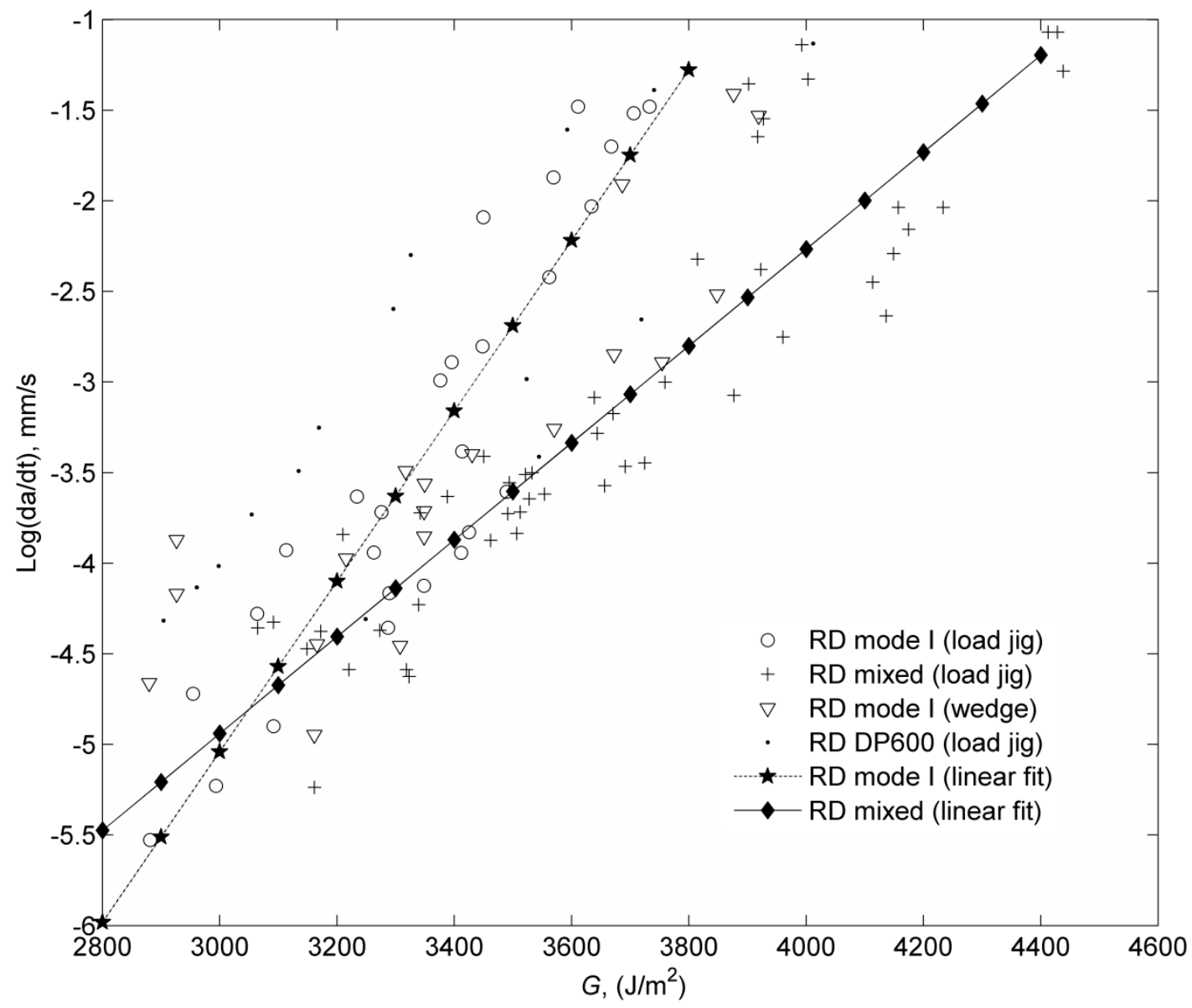

Figure 8 Crack speed vs. $G$ for creep tests. RD indicates room-dry $\left(25^{\circ} \mathrm{C} 10 \% \mathrm{RH}\right)$. Test progresses from right to left. RD mode I (load jig) is category 1 of Table 4, RD mixed (load jig, $27^{\circ}$ ) is category 2 , RD mode I (wedge) is category 3, and RD DP600 is category 4 . All mode I and all mixed-mode Data were fitted to the equation $\log (\mathrm{d} a / \mathrm{d} t)=m G+b$ where $m$ and $b$ are given in categories 1 and 2 in Table 4. Creep arrest was defined to be at $\log (\mathrm{d} a / \mathrm{d} t)=-5.4$. 


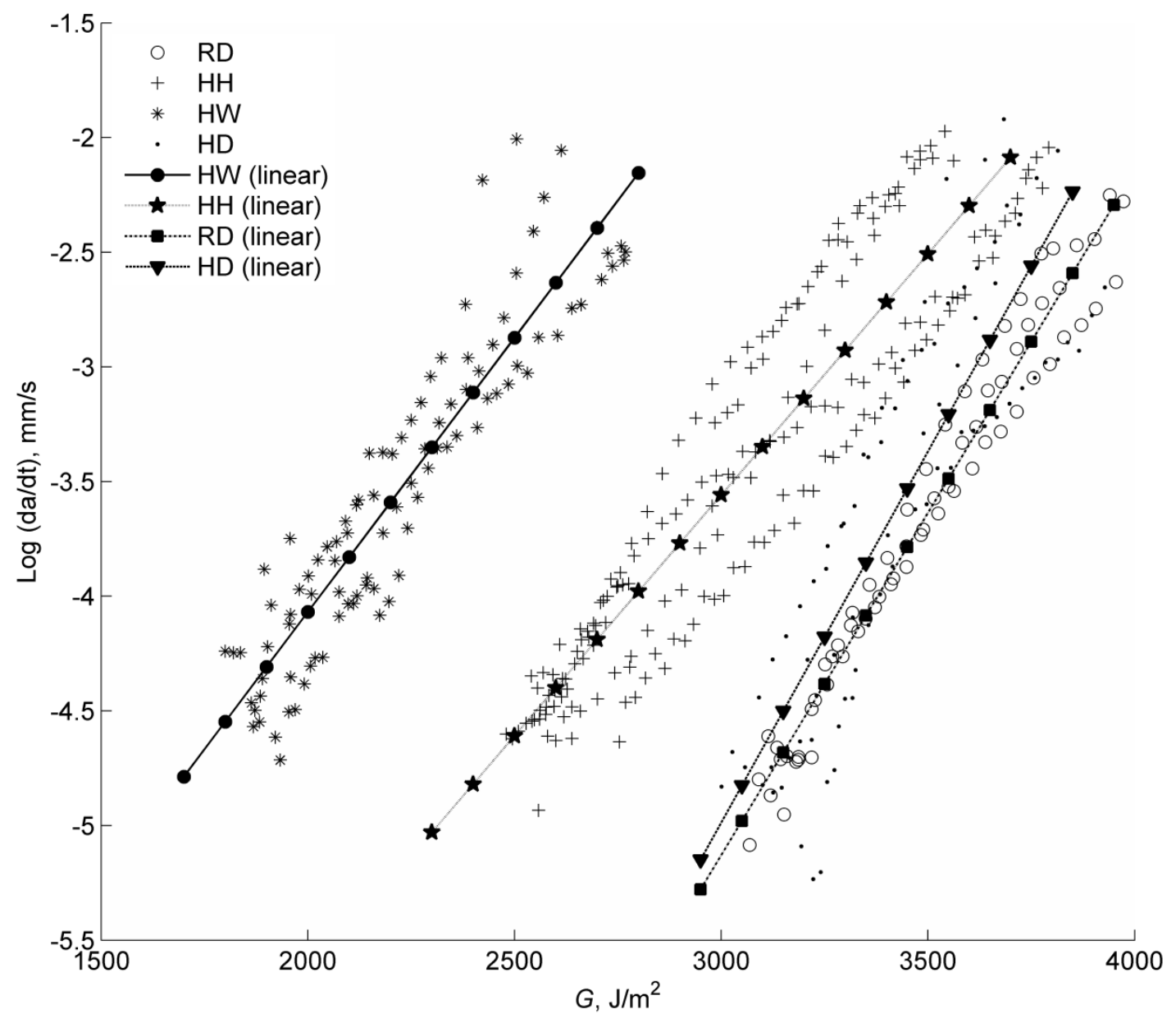

Figure 9 Environmental mode I creep test data from test in servo-hydraulic load frame. RD indicates room-dry $\left(25^{\circ} \mathrm{C} 10 \% \mathrm{RH}\right), \mathrm{HD}$ indicates hot dry $\left(40^{\circ} \mathrm{C} 10 \% \mathrm{RH}\right), \mathrm{HH}$ indicates hot humid $\left(40^{\circ} \mathrm{C} 95 \% \mathrm{RH}\right)$, and $\mathrm{HW}$ indicates hot wet $\left(40^{\circ} \mathrm{C} 100 \% \mathrm{RH}\right)$. Data were fitted to the equation $\log (\mathrm{d} a / \mathrm{d} t)=m G+b$ where $m$ and $b$ are given in categories 7, 8, 9 and 10 in Table 4 . Creep arrest was defined to be at $\log (\mathrm{d} a / \mathrm{d} t)=-5.4$. 


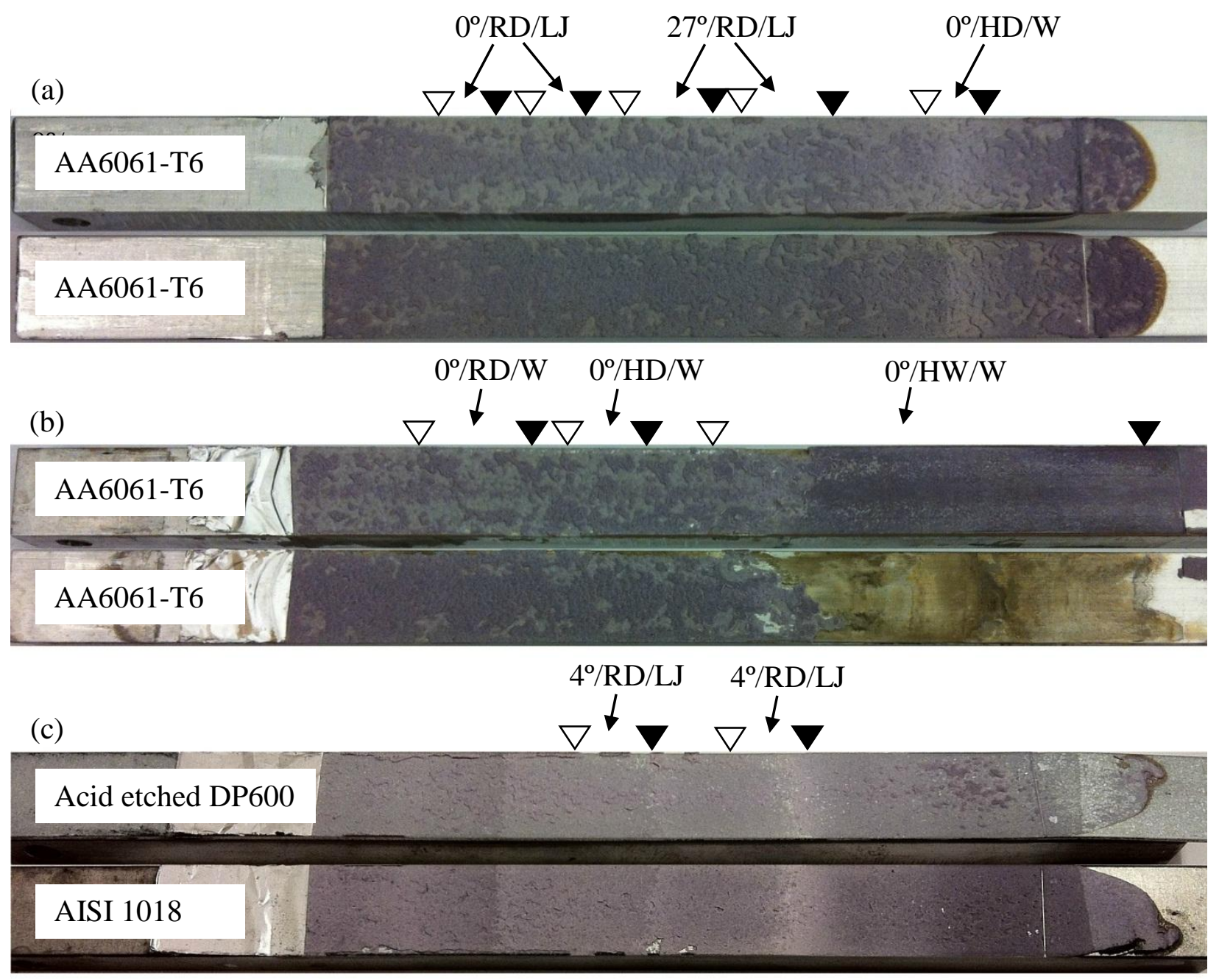

Figure 10 Creep crack growth failure surfaces. Each white and black triangle pair represent points at which $G_{c s}$ and $G_{a}$ were measured, respectively. (a) specimen 1: two mode-I load jig tests in RD (Table 4 category 1); two mixed-mode load jig tests in RD (Table 4 category 2); one wedge test in RD (Table 4 category 3); and one wedge test in HD environment (Table 4 category 5) (b) specimen 3: wedge test in RD (Table 4 category 3); wedge test in HD (Table 4 category 5); and wedge test in HW (Table 4 category 6) (c) specimen 5: DP600 and AISI1018 mode-I load jig tests in RD (Table 4 category 4$)$. 


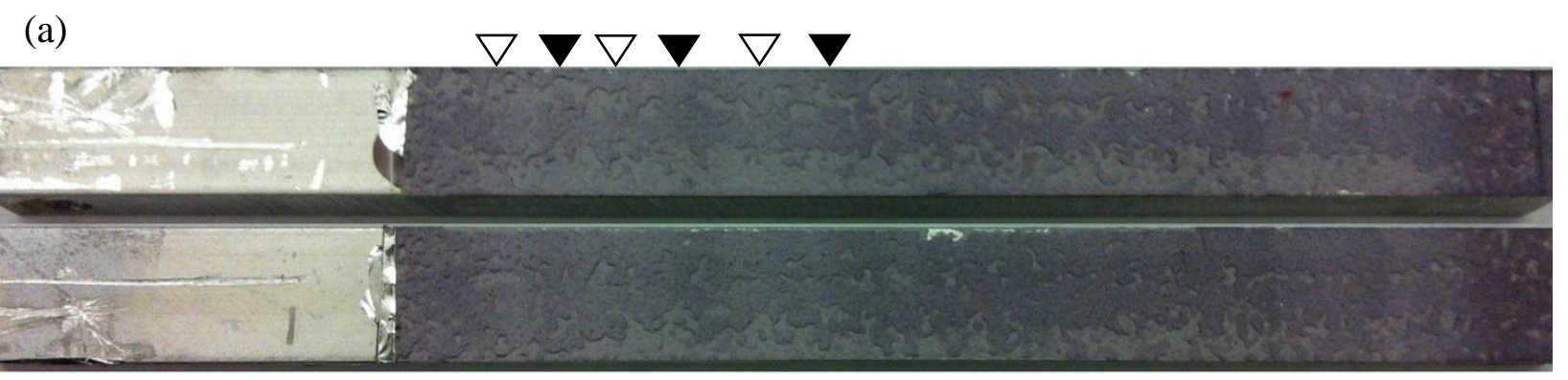

(b)

$\nabla \nabla \nabla \nabla \nabla \nabla$

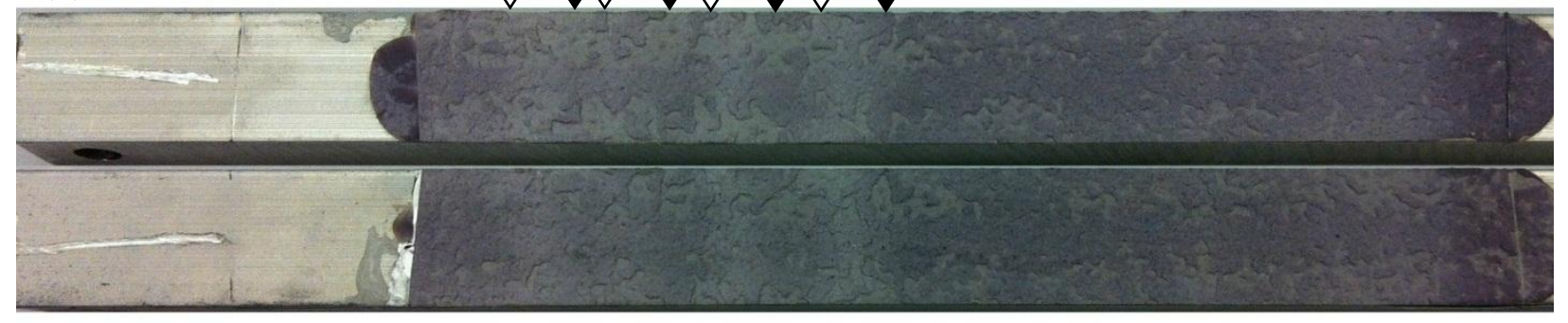

(c)

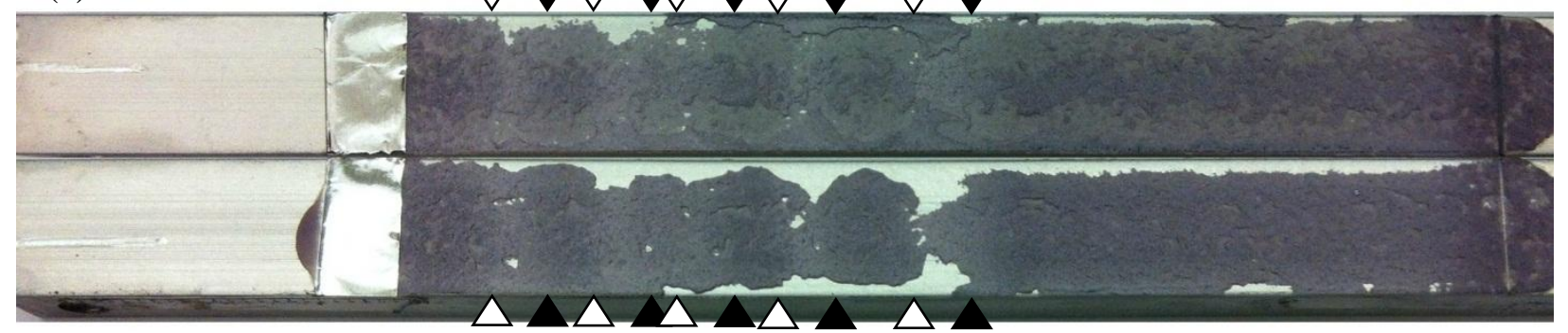

(d)
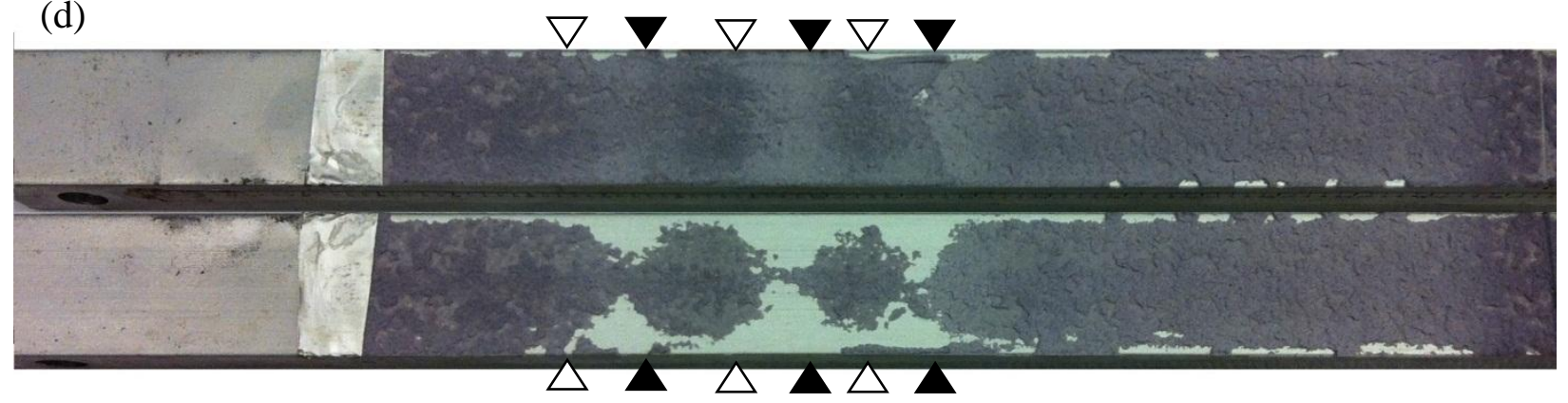

Figure 11 Creep failure surfaces of AA6061-T6 bars in: (a) RD $\left(25^{\circ} \mathrm{C} 10 \%-\mathrm{RH}\right)$ (Table 4 category 8$)$, (b) $\mathrm{HD}\left(40^{\circ} \mathrm{C} 10 \%-\mathrm{RH}\right)$ (Table 4 category 9), (c) $\mathrm{HH}\left(40^{\circ} \mathrm{C} 95 \%-\mathrm{RH}\right)$ (Table 4 category 10), and (d) $\mathrm{HW}\left(40^{\circ} \mathrm{C} 100 \%-\mathrm{RH}\right)$ (Table 4 category 11$)$. All tests were mode I and were done on the hydraulic load frame. White and black triangles indicate start and end of a $24 \mathrm{~h}$ creep test respectively. 


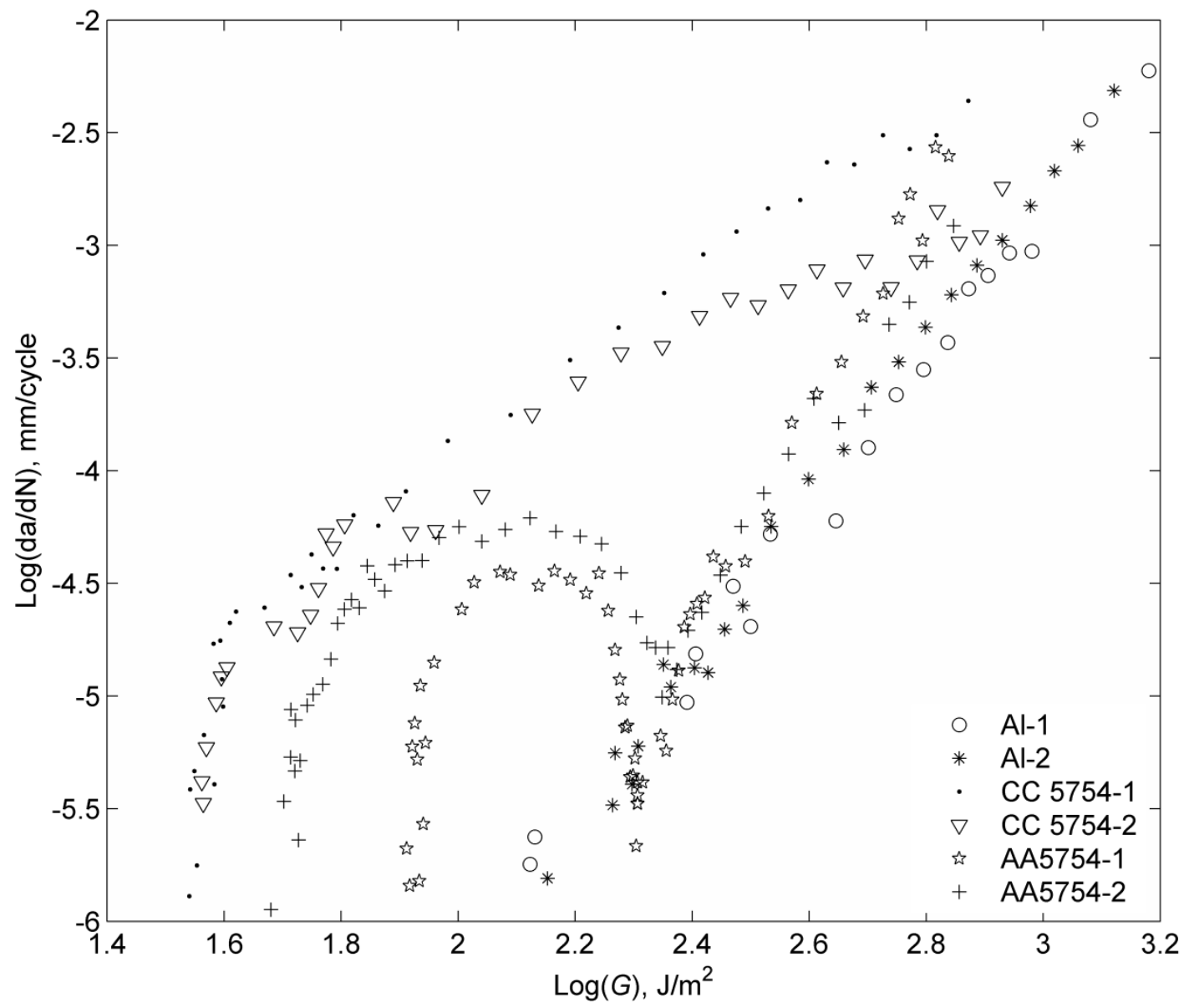

Figure 12 Fatigue crack growth for aluminum ADCB joints. Al indicates P2-etched AA6061-T6, CC 5754 indicates coil-coated AA5754-O, and AA5754 indicates degreased AA5754-O. 

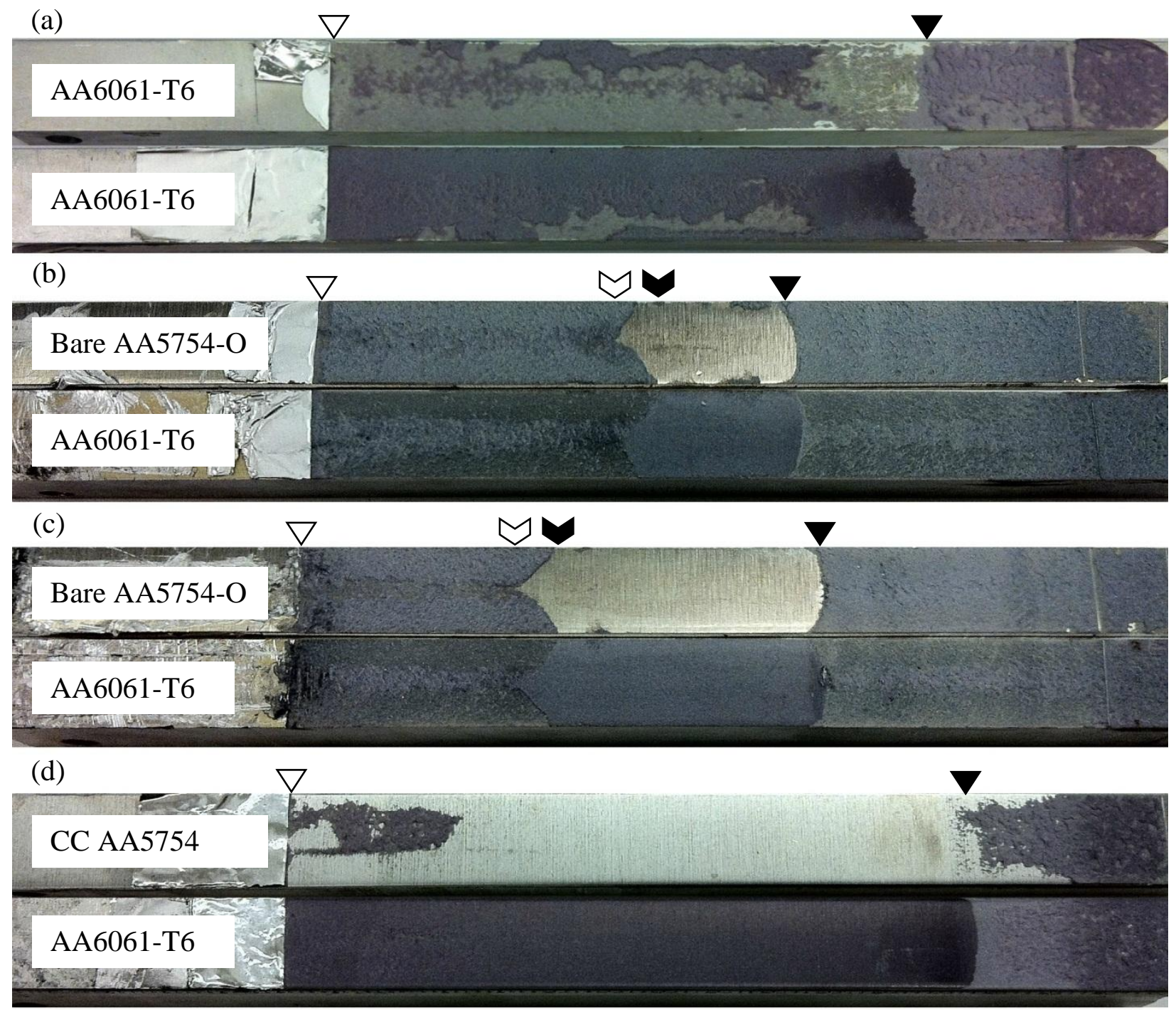

Figure 13 Mixed-mode fatigue failure surfaces of: (a) P2-etched AA6061-T6, (b), (c) bare degreased AA5057-O, (d) Coil-coated AA5754-O (Table 5). Test starts at the white triangle. White chevron indicates first instant crack front reaches the interface, and black chevron indicates first instant that $100 \%$ of crack front lands on the interface. Final threshold is indicated by black triangle. All tests at a phase angle of approximately $12^{\circ}$. Specimen was quasi-statically fractured after threshold (right of black triangle) at this phase angle. 


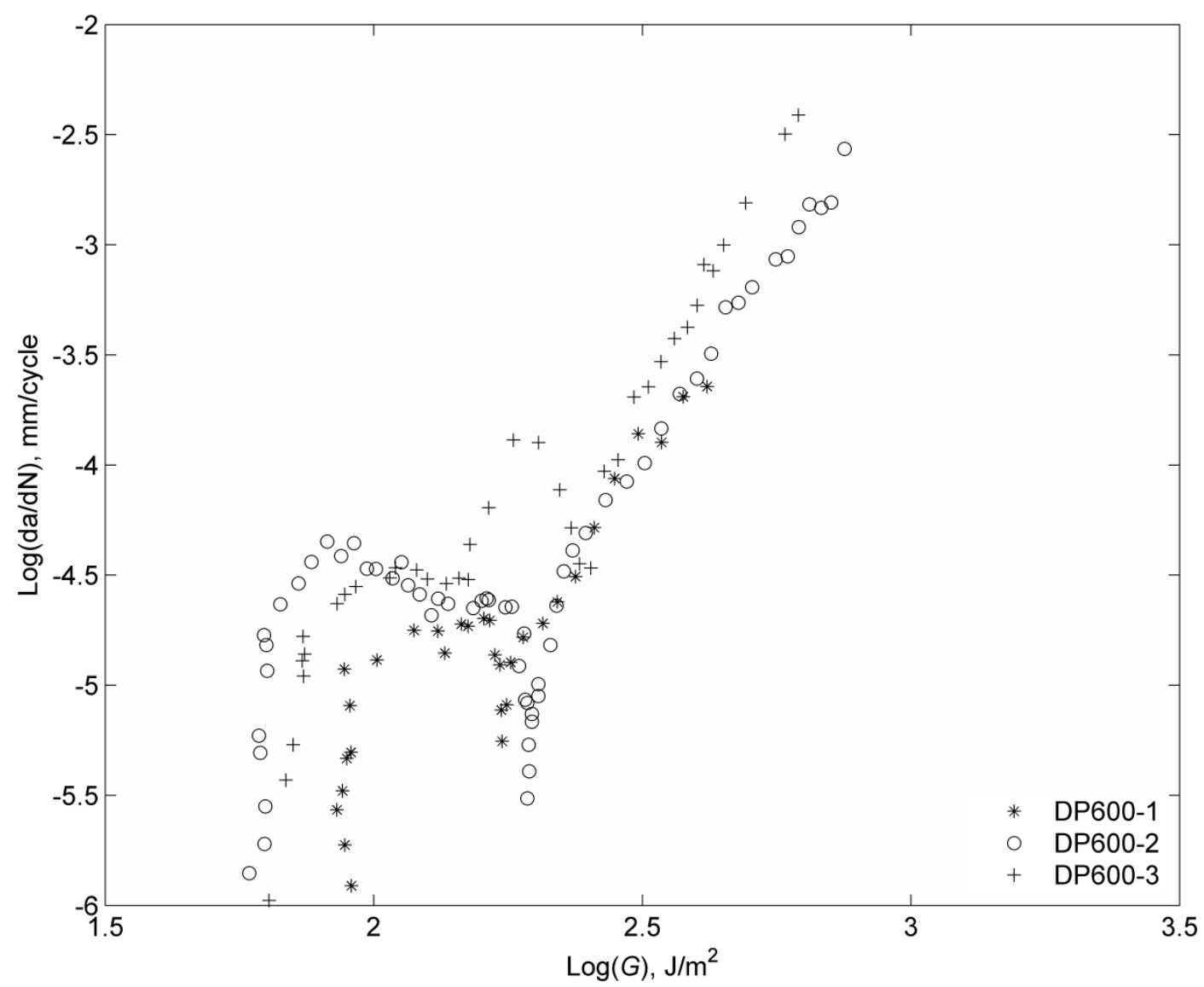

Figure 14 Fatigue crack growth for sulfuric acid etched DP600 specimens 


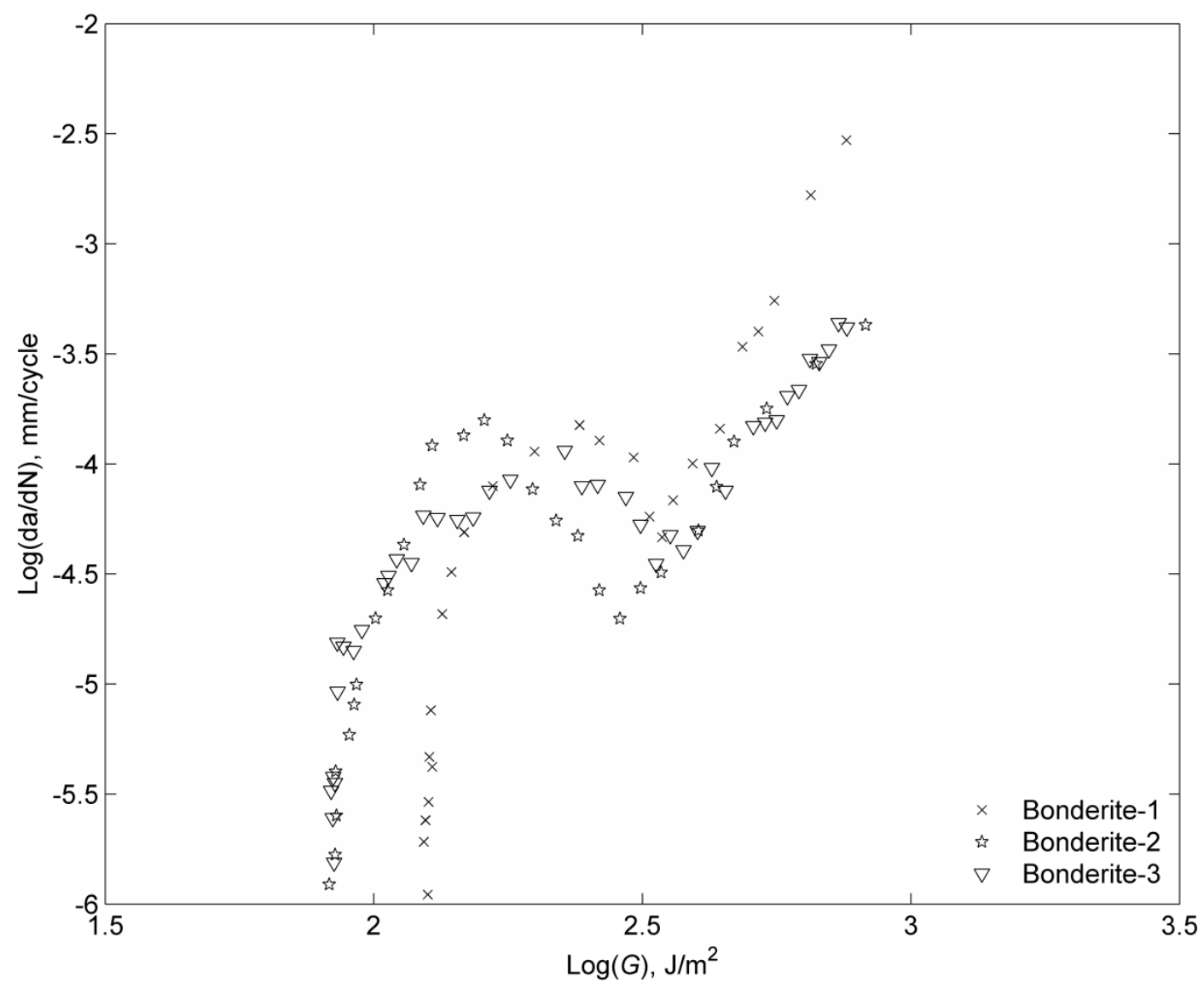

Figure 15 Fatigue crack growth for Bonderite coated DP600 specimens 

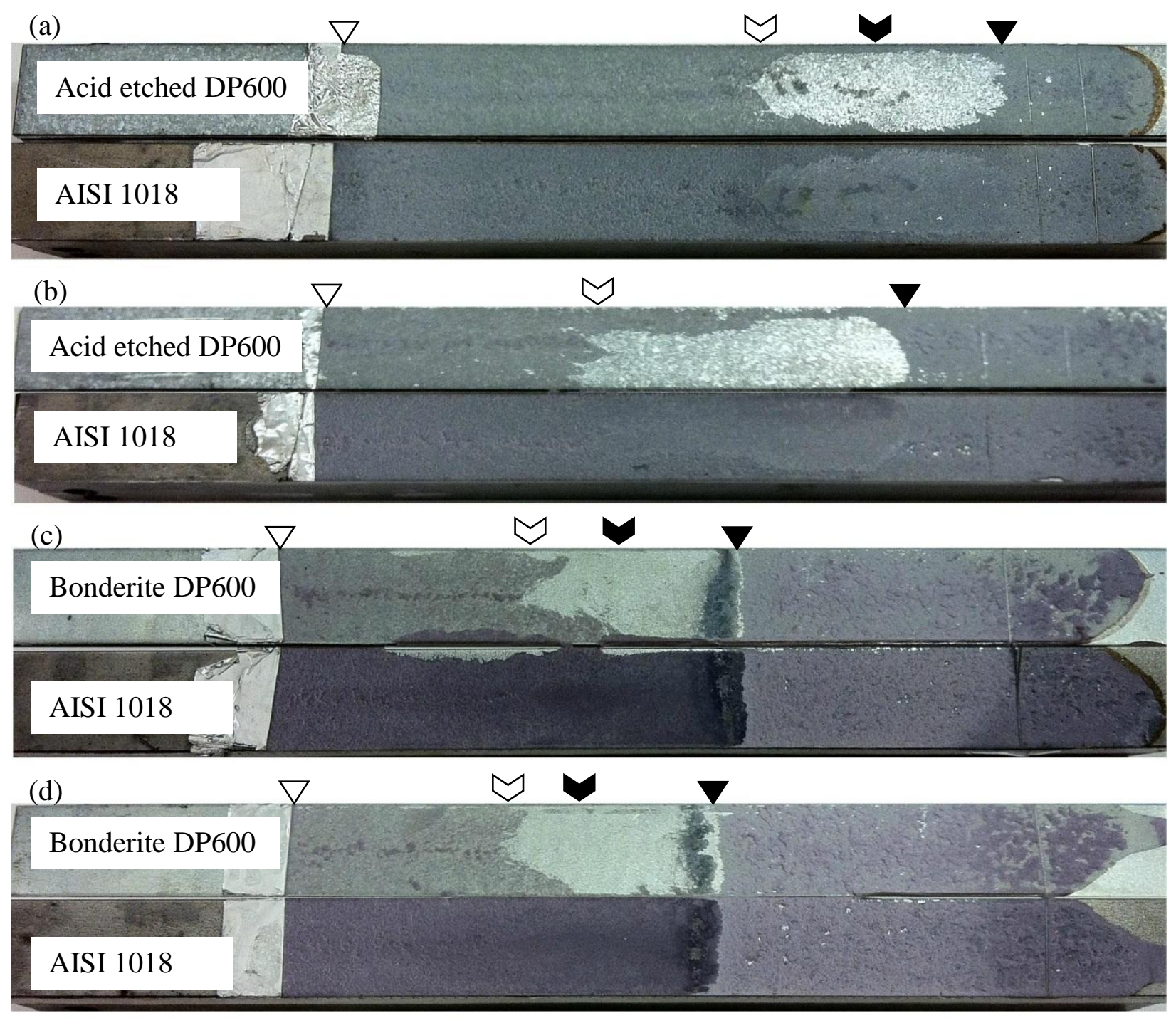

Figure 16 Fatigue failure surfaces of: (a) acid-etched DP600-2, (b) acid-etched DP600-3, (c) Bonderite $^{\mathrm{TM}}$ specimen 1, (d) Bonderite ${ }^{\mathrm{TM}}$ specimen 2 (Table 5). White chevron indicates first instant that part of crack front reached the interface, and black chevron indicates first instant that $100 \%$ of crack front reached the interface. Black triangle indicates threshold. All tests at a phase angle of approximately $12^{\circ}$. Specimen was quasi-statically fractured after threshold (right of black triangle) at this phase angle. 


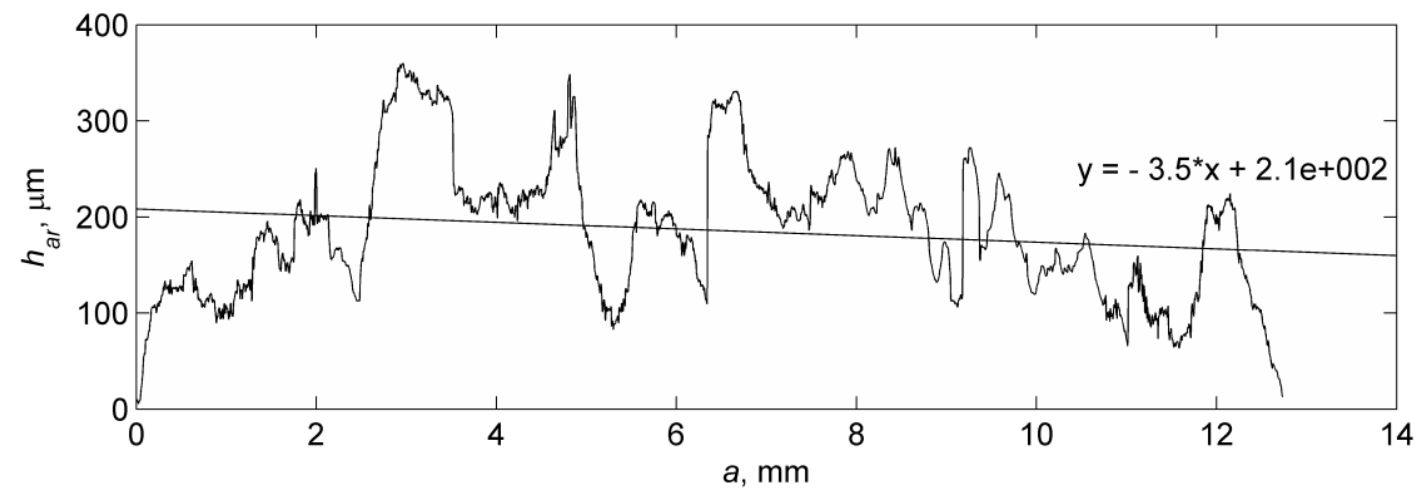

Figure 17 Residual adhesive thickness measurements along the centerline as a function of distance from the loading pins. Mode I, room temperature dry creep test of P2 etched AA6061 specimen tested on the load jig (Table 4 category 1). Equation of line of best fit shown on graph.

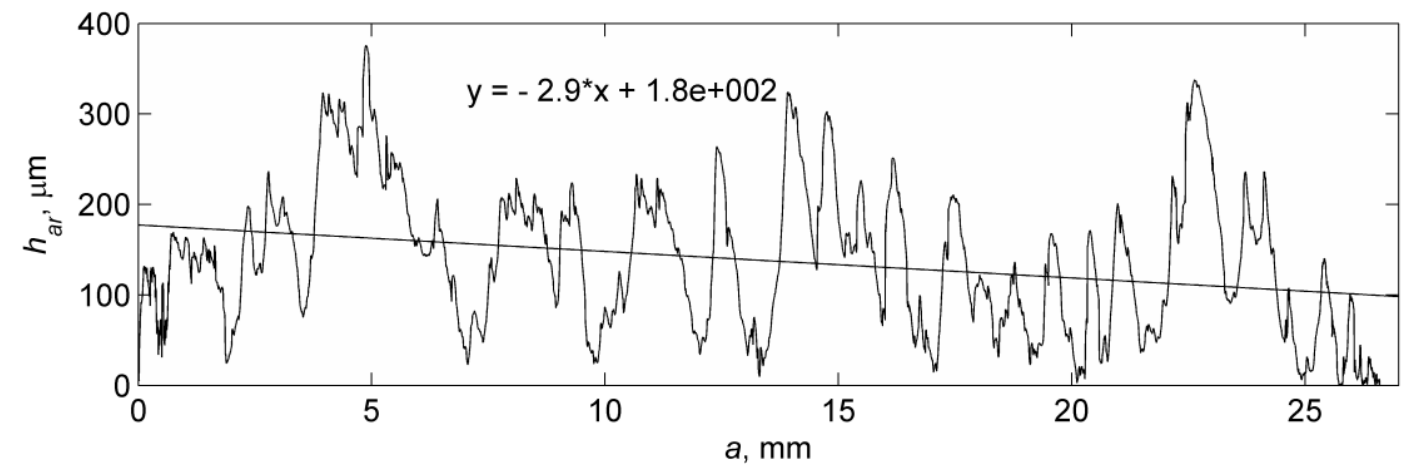

Figure 18 Residual adhesive thickness measured along the centerline as a function of distance from the loading pins. Surface was on the more highly-strained adherend for a mixed-mode ( $\Psi=$ $27^{\circ}$ ) creep specimen (room temperature dry test, P2-etched AA6061) specimen tested on the load jig (Table 4 category 2). Equation of line of best fit shown on graph. 


\section{Conclusions}

Comparisons were made of the crack paths in quasi-static fracture, creep and fatigue. This illustrated the conditions under which cohesive failure within the adhesive layer could become interfacial for a single combination of adhesive and adherend. Four factors were involved: 1. The average crack path moved closer to the more highly-strained adherend as the phase angle (mode ratio) increased. This promoted interfacial failure. 2. Cracks also moved closer to the interface of the more highly-strained adherend as the applied strain energy release rate decreased (e.g. as the fatigue threshold, $G_{t h}$, or the point of arrest of creep crack growth, $G_{a}$, was approached). This has been attributed to the corresponding decrease in the size of the crack tip plastic zone which in turn causes the crack to shift ever closer to this interface. 3. The presence of condensing water at the crack tip could induce interfacial crack growth not seen in dry environments. 4. A high interfacial bond strength could delay or eliminate the transition from cohesive to interfacial failure in all tests.

Crack growth rates under constant displacement creep conditions approaching arrest were similar to those in fatigue near the threshold; however, $G_{a}$, was much larger than $G_{t h}$. Consequently, the plastic zone size as larger in the creep tests than in the near-threshold fatigue tests, and as a result the creep crack paths were much more cohesive within the adhesive layer, similar to those observed in quasi-static fracture.

The test condition most likely to induce interfacial failure under all environmental conditions was mixed-mode fatigue near the threshold, since this caused a crack path shift toward the more highly-strained adherend, and the small applied $G$ reduced the size of the crack tip plastic zone. Adhesive joints that failed cohesively in quasi-static fracture and creep crack growth, may well fail interfacially in such fatigue tests.

If the crack path shifted from cohesive to interfacial in a fatigue test, crack growth accelerated. This produced a cusp in the fatigue crack growth rate curve in cases where the transition from cohesive to interfacial crack growth occurred abruptly. If the crack path transition was more gradual, a small plateau in the crack growth rate was observed immediately above the threshold. 
It is concluded that the presence of cohesive failure within the adhesive layer of adhesive is an unreliable indicator of joint quality. Systems that fail cohesively in fracture and creep may fail interfacially in mixed-mode fatigue, particularly near the threshold. 


\section{References}

[1] Hamoush SA, Ahmad SH. Fracture energy release rate of adhesive joints. Int J Adhes Adhes 1989;9:171-178.

[2] Ameli A, Papini M, Schroeder JA, Spelt JK. Fracture R-curve characterization of toughened epoxy adhesives. Engng Fract Mech 2010;77:521-534.

[3] Chen B, Dillard DA, Dillard JG, Clark Jr RL. Crack path selection in adhesively bonded joints: the roles of external loads and speciment geometry. Int J Fract 2002;114:167-190.

[4] Khoo TT, Kim H. Effect of bondline thickness on mixed-mode fracture of adhesively bonded joints. J Adhes 2011;87:989-1019.

[5] Madhusudhana KS, Narasimhan R. Experimental and numerical investigations of mixed mode crack growth resistance of a ductile adhesive joint. Engng Fract Mech 2002;69:865883.

[6] Ameli A, Azari S, Papini M, Spelt JK. Crack path selection in the fracture of fresh and degraded epoxy adhesive joints. Engng Fract Mech 2011;78:1986-2003.

[7] Azari S, Papini M, Schroeder JA, Spelt JK. The effect of mode ratio and bond interface on the fatigue behavior of a highly-toughened epoxy. Engng Frac Mech 2010;77:395-414.

[8] Azari S, Papini M, Schroeder JA, Spelt JK. Fatigue threshold behavior of adhesive joints. Int J Adhes Adhes 2010;30:145-159.

[9] Datla NV, Papini M, Schroeder JA, Spelt JK. Modified DCB and CLS specimens for mixedmode fatigue testing of adhesively bonded thin sheets. Int J Adhes Adhes 2010;30:439-447.

[10] Azari S, Papini M, Spelt JK. Effect of adhesive thickness on fatigue and fracture of 
toughened epoxy joints - Part I: Experiments. Engng Fract Mech 2011;78:153-162.

[11] Azari S, Papini M, Spelt JK. Effect of adhesive thickness on fatigue and fracture of toughened epoxy joints - Part II: Analysis and finite element modeling. Engng Frac Mech 2011;78:138-152.

[12] Azari S, Papini M, Spelt JK. Effect of the applied strain energy release rate on fatigue crack path selection in toughened epoxy adhesive joints. In: Proceedings of 33rd Annual Meeting of The Adhesion Society, Daytona Beach, FL; 2010. p. 307-309.

[13] Eskandarian M, Jennings R, Cote M, Arsenault B. Fracture behavior of typical structural adhesive joints under quasi-static and cyclic loadings. SAE Int. J. Mater. Manuf 2010;3(1):622-627.

[14] Plausinis D, Spelt JK. Designing for time-dependent crack growth in adhesive joints. Int J Adhes Adhes 1995;15:143-154.

[15] Fernlund G, Spelt JK. Mixed-mode fracture characterization of adhesive joints. Compos Sci Technol 1994;50:441-449.

[16] Azari S, Eskandarian M, Papini M, Schroeder JA, Spelt JK. Fracture load predictions and measurements for highly toughened epoxy adhesive joints. Engng Fract Mech 2009;76:2039-2055.

[17] Rodnyansky A, Warburton YJ, Hanke LD. Segregation in hot-dipped galvanized steel. Surf. Interface Anal. 2000;29:215-220.

[18] Foister RT, Schroeder KJ. Adhesive bonding to galvanized steel I. Lap shear strengths and environmental durability. J. Adhesion 1987;24:259-278.

[19] Foister RT. Adhesive bonding to galvanized steel II. Substrate chemistry, morphology and bond failure analysis. J. Adhesion 1987;24:279-313. 
[20] Holubka JW, Chun W, Dickie RA. Durability of adhesive bonds to Zinc-coated steels: Effect of corrosive environments on lap shear strength. J. Adhesion 1989;30:173-183.

[21] ASTM, Standard guide for preparation of metal surfaces for adhesive bonding, D2651. West Conshohocken, PA, ASTM International (2001).

[22] Datla NV, Papini M, Ulicny J, Carlson B, Spelt JK. The effects of test temperature and humidity on the mixed-mode fatigue behavior of a toughened adhesive aluminum joint. Engng Fract Mech 2011;78:1125-1139.

[23] Davies P, Protocols for interlaminar fracture testing of composites. Polymer and Composites Task Group, European Structural Integrity Society (1992).

[24] Fernlund G, Papini M, McCammond D, Spelt JK. Fracture Load Predictions for adhesive joints. Compos Sci Technol 1994;51:587-600.

[25] Krenk S. Energy release rate of symmetric adhesive joints. Engng Frac Mech 1992;43:549559.

[26] Kinloch AJ, Korenberg CF, Tan KT, Watts JF. Crack growth in structural adhesive joints in aqueous environments. J Mater Sci 2007;42:6353-6370.

[27] Fernlund G, Spelt JK. Mixed mode energy release rates for adhesively bonded beam specimens. J Comp Tech Res 1994;16(3):234-243.

[28] Rybicki EF, Kanninen MF. A finite element calculation of stress intensity factors by a modified crack closure integral. Engng Frac Mech 1977;9:931-938.

[29] Fernlund G. Analysis and fracture load predictions of structural adhesive joints. Phd Thesis, University of Toronto, Toronto, Canada, 1994. 
[30] Plausinis D, Spelt JK. Application of a new constant G load-jig to creep crack growth in adhesive joints. Int J Adhes Adhes 1995;15:225-232.

[31] Ameli A, Papini M, Spelt JK. Fracture R-curve of a toughened epoxy adhesive as a function of irreversible degredation. Mat Sci Eng A 2010;527:5105-5114.

[32] Ameli A, Papini M, Spelt JK. Hygrothermal degradation of two rubber-toughened epoxy adhesives: Application of open-faced fracture tests. Int J Adhes Adhes 2011;31:9-19.

[33] Datla NV, Ulicny J, Carlson B, Papini M, Spelt JK. Mixed-mode fatigue behavior of degraded toughened epoxy adhesive joints. Int J Adhes Adhes 2011;31:88-96.

[34] Ameli A, Papini M, Spelt JK. Evolution of crack path and fracture surface with degradation in rubber-toughened epoxy adhesive joints: Application to open-faced specimens. Int $\mathbf{J}$ Adhes Adhes 2011;31:530-540.

[35] Ameli A, Datla NV, Papini M, Spelt JK. Hygrothermal properties of highly toughened epoxy adhesives. J Adhes 2010;86:698-725.

[36] Azari S, Ameli A, Datla NV, Papini M, Spelt JK. Effect of substrate modulus on the fatigue behavior of adhesively bonded joints. Mat Sci Engng A 2012;534:594-602.

[37] ASTM, Standard test method for measurement of crack growth rates, E647. West Conshohocken, PA, ASTM International (2000). 


\section{Appendix A \\ Calculations of Specimen Loads, Strain Energy Release rates and Mode Ratios}

\section{Load jig}

The load jig in Figure 2 was capable of generating a wide range of mode ratios by adjusting the distance between the pins $\left(s_{1}-s_{4}\right)$. To give a phase angle $\Psi=0^{\circ}, s_{1}=25.4 \mathrm{~mm}, s_{2}=50.8 \mathrm{~mm}, s_{3}=$ $76.2 \mathrm{~mm}$ and $s_{4}=-50.8 \mathrm{~mm}$ and for $\Psi=27^{\circ}, s_{1}=25.4 \mathrm{~mm}, s_{2}=50.8 \mathrm{~mm}, s_{3}=76.2 \mathrm{~mm}$ and $s_{4}=$ - $25.4 \mathrm{~mm}$. The load jig was statically determinate and from equilibrium considerations of the system,

$$
\begin{gathered}
F_{1}=F\left(1-\frac{s_{1}}{s_{3}}\right) \\
F_{2}=F_{1} \frac{s_{1} / s_{2}}{1+s_{3} / s_{4}}
\end{gathered}
$$

where $F_{1}$ and $F_{2}$ are load on the top and bottom adherend pins respectively, $F$ is the load in the actuator and $s_{1}, s_{2}, s_{3}$ and $s_{4}$ are the distances between the centres of the pins shown in Figure 2. In mode $\mathrm{I}\left(\Psi=0^{\circ}\right)\left|P_{1}\right|=\left|P_{2}\right|$ and in mixed mode $\left(\Psi=27^{\circ}\right)\left|P_{1}\right|>\left|P_{2}\right|$. When $F=F_{c}$, the critical load is reached and crack growth occurs.

Strain energy release rate for DCB specimens in load jig [16]

An analytical beam-on-elastic-foundation model for calculation of the strain energy release rate in a DCB specimen has been presented in [27]. If $F_{1}$ and $F_{2}$, the load on the top and bottom adherend pins respectively, are transformed to $f_{1}$ and $f_{2}$ through the equations 


$$
\begin{gathered}
f_{1}=\frac{F_{1}-F_{2}}{2} \\
f_{2}=-\frac{F_{1}+F_{2}}{2}
\end{gathered}
$$

The energy release rate in an adhesive with a thickness $h_{a}$ is then given by

$$
G=\frac{12 a^{2}}{E\left(h-h_{a}\right)^{3}}\left[f_{1}^{2} \Phi_{\mathrm{I}}^{2}+\frac{3}{4} f_{2}^{2} \Phi_{\mathrm{II}}^{2}\right]
$$

where $a$ is the crack length, and $E$ and $h$ are, respectively, the elastic modulus and thickness of the adherends. $\Phi_{I}$ and $\Phi_{I I}$ are given by

$$
\begin{gathered}
\Phi_{\mathrm{I}}=1+0.667 \frac{h}{a}\left[\left(1-h_{a} / h\right)^{3}\left[1+h_{a} / h\left(2 E / E_{a}-1\right)\right]\right]^{0.25} \\
\Phi_{\mathrm{II}}=1+0.206 \frac{h}{a} \sqrt{\left[1-\frac{h_{a}}{h}\right]\left[1+\frac{2 h_{a} E \alpha}{G_{a} h}\right]}
\end{gathered}
$$

where $\alpha=2.946$ is a calibration constant that was determined using a finite element analysis [27]. $E_{a}$ and $G_{a}$ are the elastic and shear moduli of the adhesive, respectively. The phase angle is given by

$$
\psi=\tan ^{-1}\left[\frac{\sqrt{3}}{2} \frac{F_{2} \Phi_{\mathrm{II}}}{F_{1} \Phi_{\mathrm{I}}}\right]
$$

Strain energy release rate for $A D C B$ specimens in fatigue

The calculation of the strain energy release rate, $G$, and phase angle, $\Psi$, for ADCB specimens has been described in detail in [9] [28]. The adhesive stresses were calculated by considering the adhesive layer as an elastic foundation sandwiched between two adherends, , and used to calculate the strain energy release rate using the virtual crack closure technique [29]. 
The adhesive stresses, $\sigma$ and $\tau$, of an adhesive sandwich can be found by solving the following system of differential equations:

$$
\begin{aligned}
& \frac{d^{7} \tau}{d x^{7}}-K_{1} \frac{d^{5} \tau}{d x^{5}}+K_{3} \frac{d^{3} \tau}{d x^{3}}-\left(K_{1} K_{3}-K_{2} \frac{E_{a}}{2 t}\left[\frac{h_{1}}{D_{1}}-\frac{h_{2}}{D_{2}}\right]\right) \frac{d \tau}{d x}=0 \\
& \frac{d^{6} \sigma}{d x^{6}}-K_{1} \frac{d^{4} \sigma}{d x^{4}}+K_{3} \frac{d^{2} \sigma}{d x^{2}}-\left(K_{1} K_{3}-K_{2} \frac{E_{a}}{2 t}\left[\frac{h_{1}}{D_{1}}-\frac{h_{2}}{D_{2}}\right]\right) \sigma=0
\end{aligned}
$$

where $\mathrm{x}$ is the distance from the loaded edge of the adhesive sandwich, $K_{1}, K_{2}, K_{3}$ are constants defined by:

$$
\begin{gathered}
K_{1}=\frac{4 G_{a}}{h_{a}}\left[\frac{1}{E_{1} h_{1}}+\frac{1}{E_{2} h_{2}}\right] \\
K_{2}=\frac{6 G_{a}}{h_{a}}\left[\frac{1}{E_{1} h_{1}^{2}}+\frac{1}{E_{2} h_{2}^{2}}\right] \\
K_{3}=\frac{E_{a}}{h_{a}}\left[\frac{1}{D_{1}}+\frac{1}{D_{2}}\right]
\end{gathered}
$$

and $E, G, h$, and $D$ are the elastic modulus, shear modulus, thickness, and flexural rigidity, respectively, and the subscripts 1,2 and $a$ indicate upper adherend, lower adherend and adhesive, respectively. Assuming a relatively long specimen, the general solution of these equations for an ADCB specimen can be approximated as [9]:

$$
\begin{gathered}
\tau(x)=A_{1} e^{-a x}+e^{-b x}\left[A_{2} \cos (c x)+A_{3} \sin (c x)\right]+\frac{V_{1}+V_{2}}{2 I_{0}} h_{1} h_{2} \\
\sigma(x)=B_{1} e^{-a x}+e^{-b x}\left[B_{2} \cos (c x)+B_{3} \sin (c x)\right]
\end{gathered}
$$

where coefficients $A_{1}, A_{2}, A_{3}, B_{1}, B_{2}$ and $B_{3}$ are determined by system of equations described in Appendix A of ref. [9]. $V_{1}$ and $V_{2}$ are shear forces per unit width acting at the pins on the upper and lower adherends respectively and $I_{0}=\left(h_{1}+h_{2}\right)^{3} / 12$, the second moment of inertia of the specimen. 
Given the calculated stress field, the mode I and mode II strain energy release rates are given by the equations below [28]:

$$
\begin{gathered}
G_{I}=h_{a} \frac{\sigma^{2}(0)}{2 E_{a}} \\
G_{I I}=h_{a} \frac{\tau^{2}(0)}{2 G_{a}}
\end{gathered}
$$

The mixed mode strain energy release rate and the mode ratio are given by:

$$
\begin{gathered}
G=G_{I}+G_{I I} \\
|\psi|=\tan ^{-1} \sqrt{\frac{G_{I I}}{G_{I}}}
\end{gathered}
$$

Note that when the upper and lower adherends are equal, $K_{2}=0$, the differential equations are decoupled and the analysis is simplified. 


\section{Appendix B \\ Additional References}

Quasi-static Fracture

[B1] Taib AA, Boukhili R, Achiou S, Gordon S, Boukehili H. Bonded joints with composite adherends. Part I. Effect of specimen configuration, adhesive thickness, spew fillet and adherend stiffness on fracture. Int J Adhes Adhes 2006;26:226-236.

[B2] Park S, Dillard DA. Development of a simple mixed-mode fracture test and the resulting fracture energy envelope for an adhesive bond. Int J Fract 2007;147:261-271.

[B3] Lee DB, Ikeda T, Miyazaki N, Choi NS. Effect of Bond Thickness on the Fracture Toughness of Adhesive Joints. J Eng Mater Technol 2004;126:14-18.

[B4] Khoo TT, Kim H. Effect of Bondline Thickness on Mixed-Mode Fracture of Adhesively Bonded Joints. J Adhesion 2011;87:989-1019.

[B5] Ji G, Ouyang Z, Li G, Ibekwe S, Pang Ss. Effects of adhesive thickness on global and local Mode-I interfacial fracture of bonded joints. Int J Solids Struct 2010;47:2445-2458.

[B6] Yan C, Mai YW, Yuan Q, Ye L, Sun J. Effect of substrate materials on fracture toughness measurement in adhesive joints. Int J Mech Sci 2001;43:2091-2102.

[B7] Madhusudhana KS, Narasimhan R. Experimental and numerical investigations of mixed mode crack growth resistance of a ductile adhesive joint. Engng Fract Mech 2002;69:865-883. 


\section{Creep Crack Growth}

[B8] Majeda P, Skrodzewicz J. A modified creep model of epoxy adhesive at ambient temperature. Int J Adhes Adhes 2009;29:396-404.

[B9] Khalili SMR, Jafarkarimi MH, Abdollahi MA. Creep analysis of fibre reinforced adhesives in single lap joints_Experimental study. Int J Adhes Adhes 2009;29:656-661.

[B10] Finogenov GN. Creep Assessment Procedure for Adhesive Joints. Polym Sci 2007;49:1920.

[B11] Tsou AH, DelleFave DL. Creep of a glass-flake-reinforced epoxy adhesive for space applications. Polymer 1996;37:5381-5386.

[B12] Chen QQ, Xuan FZ, Tu ST. Effects of creep on interfacial stresses of bonded structures. Mat Sci Eng A 2008;497:471-478.

[B13] Palazotto AN, Birman V. Environmental and viscoelastic effects on stresses in adhesive joints. J Aerospace Eng 1995;8:107-118.

[B14] Meshgin P, Choi KK, Reda Taha M. Experimental and analytical investigations of creep of epoxy adhesive at the concrete-FRP interfaces. Int J Adhes Adhes 2009;29:56-66.

[B15] Feng CW, Keong CW, Hsueh YP, Wang YY, Sue HJ. Modeling of long-termcreep behavior of structural epoxy adhesives. Int J Adhes Adhes 2005;25:427-436.

[B16] Dean G. Modelling non-linear creep behaviour of an epoxy adhesive. Int J Adhes Adhes 2007;27:636-646.

[B17] Hughes EJ, Rutherford JL. Stress Dependence of Creep in Bonded Adhesives. Mat Sci Eng 1980;44:57-62.

[B18] Su N, Mackie RI. Two-dimensional creep analysis of structural adhesive joints. Int J Adhes Adhes 1992;13:33-40. 


\section{Fatigue}

[B19] Gomatam RR, Sancaktar E. A novel cumulative fatigue damage model for electronicallyconductive adhesive joints under variable loading. J Adhes Sci Technol 2005;20:69-86.

[B20] Pirondi A, Moroni F. An investigation of fatigue failure prediction of adhesively bonded metal/metal joints. Int J Adhes Adhes 2009;29:796-805.

[B21] de Goeij WC, van Tooren MJL, Beukers A. Composite adhesive joints under cyclic loading. Mater Design 1999;20:213-221.

[B22] Casas-Rodriguez JP, Ashcroft IA, Silberschmidt VV. Delamination in adhesively bonded CFRP joints: Standard fatigue, impact-fatigue and intermittent impact. Compos Sci Technol 2008;68:2401-2409.

[B23] Krenk S, Jonsson J, Hansen LP. Fatigue analysis and testing of adhesive joints. Engng Fract Mech 1996;53:859-872.

[B24] Fernando M, Harjoprayitno WW, Kinloch AJ. A fracture mechanics study of the influence of moisture on the fatigue behaviour of adhesively bonded aluminium-alloy joints. Int $\mathbf{J}$ Adhes Adhes 1996;95:113-119.

[B25] Ashcroft IA, Shaw SJ. Mode I fracture of epoxybonded composite joints 2. Fatigue loading. Int J Adhes Adhes 2002;22:151-167.

[B26] Kelly G. Quasi-static strength and fatigue life of hybrid (bonded/bolted) composite single-lap joints. Compos Struct 2006;72:119-129.

[B27] Pereira AM, Ferreira JM, Antunes FV, Bartolo PJ. Study on the fatigue strength of AA6082-T6 adhesive lap joints. Int J Adhes Adhes 2009;29:633-638.

[B28] Underhill PR, DuQuesnay DL. The dependence of the fatigue life of adhesive joints on surface preparation. Int J Adhes Adhes 2006;26:62-66. 
[B29] Rushforth MW, Bowen P, McAlpine E, Zhou X, Thompson GE. The effect of surface pretreatment and moisture on the fatigue performance of adhesively-bonded aluminium. J Mater Process Technol 2004;153-154:359-365.

[B30] Lefebvre DR, Ahn BK, Dillard DA, Dillard JG. The effect of surface treatments on interfacial fatigue crack initiation in aluminum/epoxy bonds. Int J Fract 2002;114:191-202.

[B31] Gomatam RR, Sancaktar E. The effects of stress state, loading frequency and cyclic waveforms on the fatigue behavior of silver-filled electronically-conductive adhesive joints. $J$ Adhes Sci Technol 2006;20:53-68. 